\title{
Relocate 10 billion livestock to reduce harmful nitrogen pollution exposure for $90 \%$ of China's population
}

\author{
Zhaohai Bai ${ }^{1,2,3,7 凶}$, Xiangwen Fan ${ }^{1,7}$, Xinpeng Jin ${ }^{1,7}$, Zhanqing Zhao ${ }^{4}$, Yan Wu ${ }^{5}$, Oene Oenema ${ }^{2}$, \\ Gerard Velthof ${ }^{6}$, Chunsheng $\mathrm{Hu}^{1}$ and $\mathrm{Lin} \mathrm{Ma}{ }^{1}{ }^{1 凶}$
}

\begin{abstract}
Livestock production in China is increasingly located near urban areas, exposing human populations to nitrogen pollution via air and water. Here we analyse livestock and human population data across 2,300 Chinese counties to project the impact of alternative livestock distributions on nitrogen emissions. In 2012 almost half of China's livestock production occurred in peri-urban regions, exposing $60 \%$ of the Chinese population to ammonia emissions exceeding UN guidelines. Relocating 5 billion animals by 2050 according to crop-livestock integration criteria could reduce nitrogen emissions by two-thirds and halve the number of people exposed to high ammonia emissions. Relocating 10 billion animals away from southern and eastern China could reduce ammonia exposure for $\mathbf{9 0} \%$ of China's population. Spatial planning can therefore serve as a powerful policy instrument to tackle nitrogen pollution and exposure of humans to ammonia.
\end{abstract}

hina is suffering from severe environmental pollution caused by nitrogen emissions from agriculture, industry and traffic. These emissions contribute to high ammonia $\left(\mathrm{NH}_{3}\right)$, nitrogen oxide $\left(\mathrm{NO}_{x}\right)$ and particulate matter $\left(\mathrm{PM}_{25}\right)$ concentrations in the air $^{1,2}$, and to eutrophication of surface waters and groundwater ${ }^{3}$. A substantial fraction of the nitrogen losses to air and water bodies originates from the livestock production-consumption chain ${ }^{4,5}$, which is partly due to the increasing decoupling of crop production and livestock production at farm level ${ }^{6,7}$. However, the geographic segregation of crop and livestock production systems and the concentration of livestock production in few regions have received less attention.

Based on the regional-level ratio of livestock manure nitrogen excretion to maximal manure nitrogen application to cropland, livestock production is unevenly distributed in China ${ }^{6,8}$. Livestock production is concentrated in a few regions in China and consequently manure nutrient excretion exceeds the nutrient uptake capacity of local cropland in these regions ${ }^{9-11}$. Transportation of manure to distant cropland is costly, due to its high water content, and hence unprocessed manure is rarely transported over large distances and is often discharged to the environment directly ${ }^{12}$. Hence, an uneven distribution of livestock production, in particular a high livestock density near urban areas, may lead to a high proportion of the population being exposed to multiple pollutants in the air and in watercourses.

The demand for livestock products will increase in China in the coming decades ${ }^{13-15}$ and it is important to know where the additional livestock should be raised. It has been suggested that a geographically explicit recoupling of crop and livestock production systems would minimize the risk of high nutrient losses, create a situation with a better and more uniform environmental quality, and keep livestock farms at safe distances from residential areas ${ }^{6,7,16}$. This requires spatial planning of livestock production across and within regions. As a co-benefit of livestock spatial planning, the recycling and utilization of phosphorus and other nutrients, and of organic matter, can be made more efficient ${ }^{17,18}$. However, little quantitative information is currently available about the impacts of an improved spatial distribution of livestock farms. The objectives of our study are: (1) to analyse the driving forces and impacts of spatial distributions of livestock production in China for the period 19902012; and (2) to explore the possible impacts of a spatially more even distribution of livestock production on nitrogen use and losses in 2050. We focus on nitrogen because of the severity of nitrogen pollution in China and for reasons of brevity. The NUtrient flows in Food chains, Environment and Resources use (NUFER) model was adjusted and a multicriteria-based livestock spatial planning concept was developed for the purpose of this study.

\section{Results}

Unevenly distributed livestock production. The livestock population in China increased by $80 \%$ between 1990 and 2012, from 240 to 430 million standard livestock units (LU). A standard livestock unit equals a $500 \mathrm{~kg}$ dairy $\operatorname{cow}^{19}$. About $98 \%$ of the increase occurred to the right of the Huhuanyong Line (Hu Line) (Fig. 1a,c). The main livestock production counties (that is, counties with more than $320,000 \mathrm{LU}$ ), contributed $9.2 \%$ to the total LU in 1990 and $55 \%$ in 2012 (Fig. 1a,c and Extended Data Fig. 1). The geographic connection between crop and livestock production greatly decreased between 1990 and 2012, as reflected by the rapid increase in livestock density and the increasing ratio of annual manure nitrogen excretion to annual crop nitrogen uptake in some counties (Fig. 1b,d and Extended Data Fig. 2). Over $37 \%$ of the counties to the right of the

${ }^{1}$ Key Laboratory of Agricultural Water Resources, Hebei Key Laboratory of Soil Ecology, Center for Agricultural Resources Research, Institute of Genetic and Developmental Biology, Chinese Academy of Sciences, Shijiazhuang, China. ${ }^{2}$ Wageningen University, Soil Quality Group, Wageningen, Netherlands. ${ }^{3}$ Xiongan Institute of Innovation, Chinese Academy of Sciences, Beijing, China. ${ }^{4}$ School of Land Science and Space Planning, Hebei GEO University, Shijiazhuang, China. ${ }^{5}$ Zhejiang University City College, Hangzhou, China. ${ }^{6}$ Wageningen Environmental Research, Wageningen, Netherlands.

${ }^{7}$ These authors contributed equally: Zhaohai Bai, Xiangwen Fan, Xinpeng Jin. ${ }^{-}$-mail: baizh1986@126.com; malin1979@sjziam.ac.cn 
a

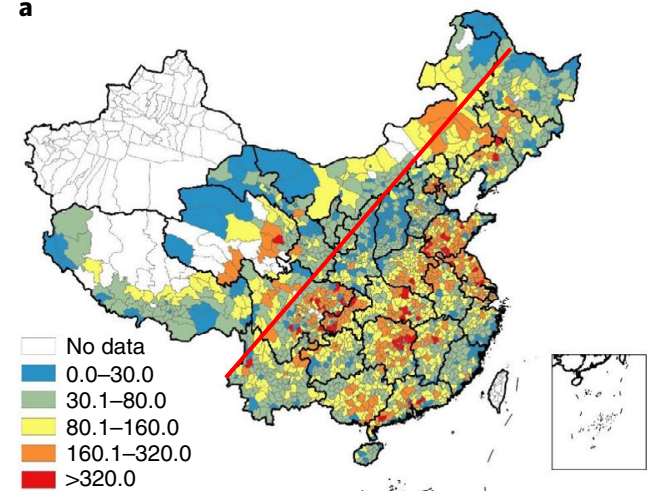

c

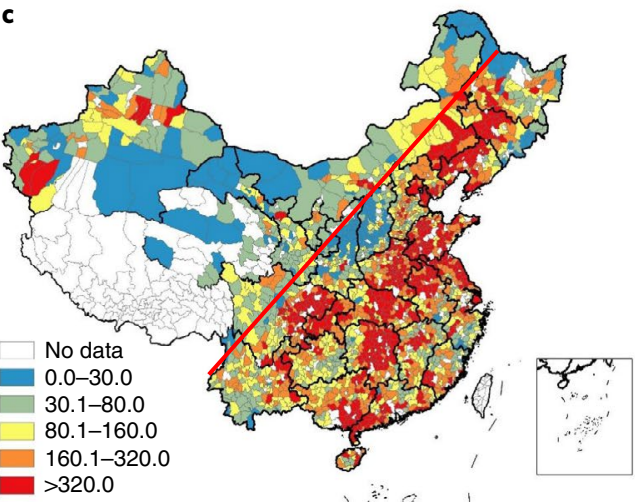

b

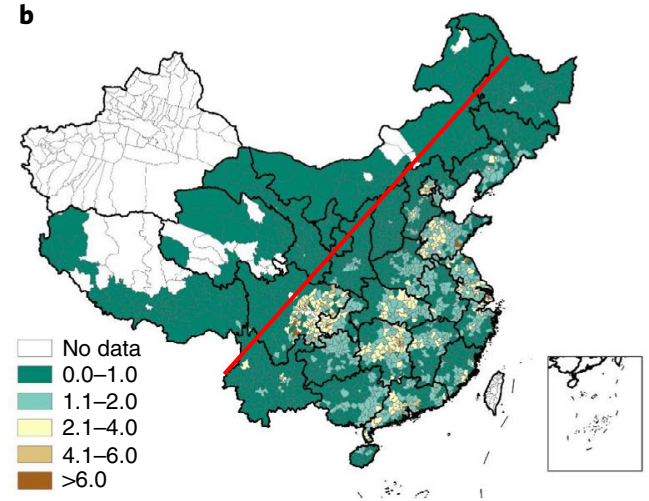

d

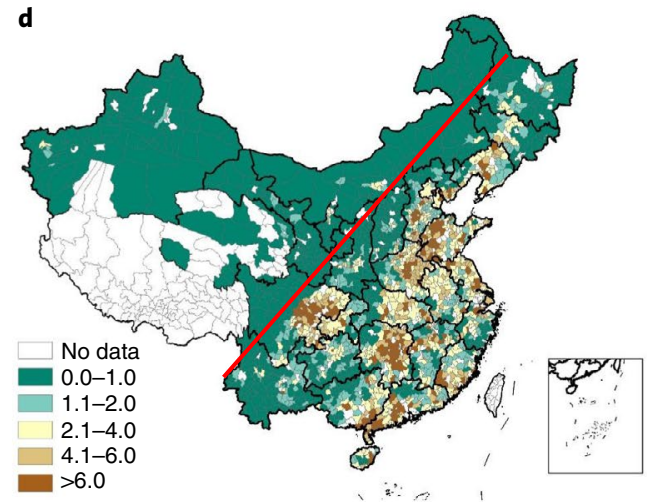

Fig. 1 | Geographic distribution of livestock production. a-d, Maps describing livestock production in terms of livestock population (1,000 LU) (a,c) and livestock density (LU per hectare of agricultural land) (b,d) at county level in China in 1990 (a,b) and 2012 (c,d). Note: there are 34 provinces and 2,850 counties in China. The red line represents the Huhuanyong Line.

Hu Line had a livestock density $>4.0 \mathrm{LU} \mathrm{ha}^{-1}$ in 2012 (Fig. 1b,d and Extended Data Fig. 1). For comparison, Denmark regulates maximum livestock density to $2.0 \mathrm{LU} \mathrm{ha}^{-1}$ to limit nutrient pollution by livestock production ${ }^{20}$. A livestock density of $\leq 2 \mathrm{LU} \mathrm{ha}^{-1}$ is a rough indication that the produced manure nutrients can be absorbed by the growing crops in that area, depending also on soil and climatic conditions and management.

The concentration of livestock production in regions is not unique to China; it has been observed in many developed and emerging countries, including the United States (Extended Data Fig. 3). The ratio of annual manure nitrogen excretion to annual crop nitrogen uptake was $>2.0$ in $11 \%$ of the 3,100 counties in the United States in 1992 and in 22\% of the counties in 2012. The contribution of these counties to the total manure nitrogen production has increased from 21\% to 32\% between 1992 and 2012 21 (Extended Data Fig. 3). Although the United States and China have roughly similar areas of land and cropland, the numbers of humans and livestock are much larger in China, and hence the concentrations of humans and livestock in specific regions are much higher in China than in the United States (Extended Data Figs. 2 and 3). The ratio of synthetic fertilizer nitrogen use to crop nitrogen uptake has a different geospatial trend to the ratio of manure nitrogen excretion to crop nitrogen uptake in the United States than in China. This suggests that more manure nitrogen was recycled effectively and substituted for synthetic fertilizer nitrogen in the United States than in China. This has resulted in a relatively low fertilizer nitrogen application rates in livestock-dense regions in the United States compared with those in China in 2012 (Extended Data Fig. 3).

Driving forces of uneven livestock distribution. The location of livestock farms is influenced by several factors, such as vicinity of markets, traffic infrastructure, availability of animal feed, availability of animal health and epidemic prevention services, and slaughter and milk processing services ${ }^{9,22-24}$. Concentration of livestock production near markets contributes to improving livestock production efficiency, lowering production costs and shortening the delivery distances ${ }^{25,26}$. Our panel data analysis showed that the livestock production of a county was significantly and positively correlated with human population and gross domestic product, suggesting that the thickness of local demand played an important role in shaping the geospatial patterns of livestock production during the period 1990-2012 (Extended Data Table 1). River intensity had a significant positive correlation with livestock density in the no-fixed-effects model (Extended Data Table 1). Feed availability (measured by the production of maize and soybean of a county) and feed accessibility (measured by the road length of a county) were also not significantly related to livestock density in the fixed-effects model analysis (Extended Data Table 1).

Nitrogen pollution impacted by unevenly distributed livestock. There were positive correlations between livestock density, $\mathrm{NH}_{3}$ emissions and nitrogen losses to water in counties in 1990 and 2012 (Fig. 2). There was also positive correlation between livestock density and average synthetic nitrogen fertilizer use per hectare of cropland in counties in 1990 and 2012, which indirectly suggests that little or no synthetic fertilizer nitrogen was replaced by animal manure nitrogen (Fig. 2). The slightly higher slope of the linear regression between livestock density and $\mathrm{NH}_{3}$ emission intensity in 1990 than in 2012 is probably related to lower crop-livestock integration and to improved animal feeding in 2012 compared to 1990. The uneven distribution of livestock production at county level led to a summed manure surplus of $1.8 \mathrm{TgN}$ in 1990 and of $4.6 \mathrm{TgN}$ 

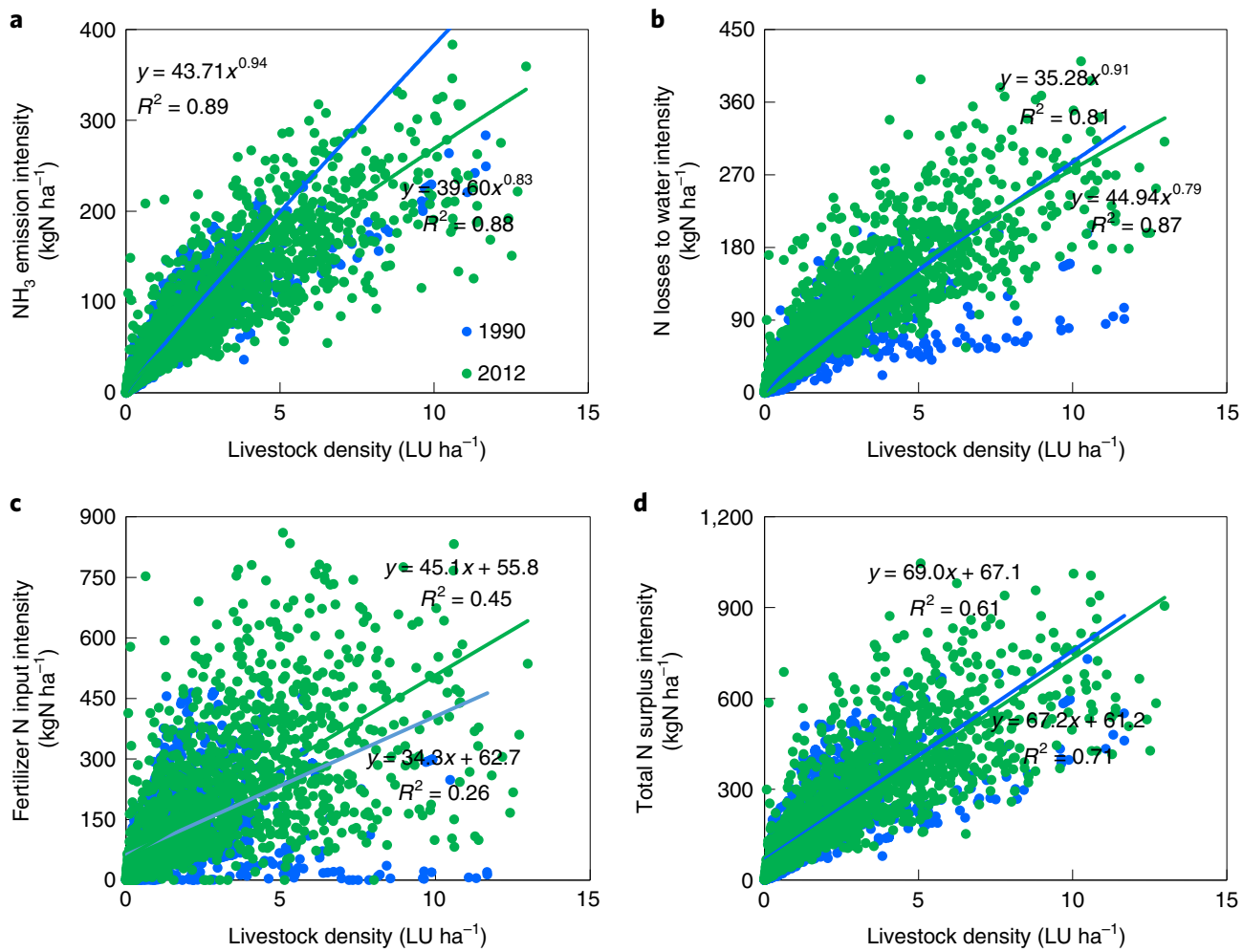

Fig. 2 | Relationships between livestock density, $\mathbf{N H}_{3}$ emissions and nitrogen losses in 1990 and 2012. a-d, Relationships between livestock density and average $\mathrm{NH}_{3}$ emission intensity (a), reactive nitrogen losses to surface waters (b), synthetic nitrogen fertilizer use (c) and total nitrogen surplus (d) (including the nitrogen from synthetic fertilizer) at county level in 1990 and 2012. Counties with average livestock density $>3$ times the standard deviation of the average livestock density ( $3.7 \mathrm{LU} \mathrm{ha}^{-1}$ in 1990 and $4.3 \mathrm{LU} \mathrm{ha}^{-1}$ in 2012) were excluded from the analysis. The calculated $\mathrm{NH}_{3}$ emissions are not independent of livestock density because a higher livestock density usually produces more manure nitrogen which is vulnerable to $\mathrm{NH}_{3}$ emissions. The blue dots represent data in 1990, and green dots represent data in 2012.

in 2012 (Fig. 3b). Manure nitrogen surplus is defined here as the difference between total manure nitrogen excretion and total crop nitrogen demand, corrected for the supply of nitrogen by soil, crop residues, waste, biological $\mathrm{N}_{2}$ fixation and atmospheric deposition (thus without synthetic fertilizer nitrogen), at county level (for more detail, see equation (3)). Hence, this manure nitrogen surplus could not be recycled in cropland and thus was largely lost to air and water bodies $^{5}$. At the same time, there was a rapid increase in synthetic nitrogen fertilizer use, which hindered the effective recycling of livestock manure nitrogen further ${ }^{3,5}$.

Average airborne $\mathrm{PM}_{2.5}$ concentrations in a county were more positively correlated with livestock nitrogen excretion per county, rather than with fertilizer nitrogen input, or with airborne $\mathrm{SO}_{2}$ and $\mathrm{NO}_{x}$ concentrations (Extended Data Fig. 4). Regions with high airborne $\mathrm{PM}_{25}$ concentrations correlated with regions with high livestock density. High $\mathrm{PM}_{2.5}$ concentrations contribute to respiratory diseases; there were 1.8 million people aged $>65$ years with premature mortality related to $\mathrm{PM}_{25}$ exposure in China in $2012^{27}$, and over $60 \%$ of these deaths occurred in regions in which $\mathrm{PM}_{25}$ concentration was substantially correlated with livestock nitrogen excretions (Extended Data Fig. 4).

Impacts of livestock production in 2050. It is probable that China will continue to suffer from unevenly distributed livestock production in the near future, especially with the predicted increase in the demand for livestock products. Domestic crop production and livestock production are projected to increase by $20 \%$ and $40 \%$, respectively, in terms of protein production between 2012 and 2050 according to a business-as-usual (BAU) scenario ${ }^{28}$. As a result, total
$\mathrm{NH}_{3}$ emissions and nitrogen losses to water bodies will increase by $12 \%$ between 2012 and 2050 (Fig. 3c,d). The modest increases of nitrogen losses to the environment in the BAU scenario reflect the balance between the expected increased production and hence increased nitrogen losses, and the expected impacts of policies and measures to decrease these losses (for example, Zero Fertilizer Action $^{29,30}$, improved crop husbandry practices, improved irrigation and nutrient management ${ }^{31,32}$ and the replacement of fertilizer nitrogen by manure nitrogen ${ }^{33}$ ). The policies and measures together will reduce the average nitrogen losses per unit of crop product and especially per unit of animal product produced.

Around $26 \%$ of counties will have a livestock density $>4.0 \mathrm{LU} \mathrm{ha}^{-1}$ and these counties will accommodate $58 \%$ of total LU in the BAU scenario in 2050 (Fig. 4a and Extended Data Fig. 1). This will result in a summed manure nitrogen surplus of $11 \mathrm{Tg}$; a surplus that cannot be recycled to cropland in an economically feasible and environmentally sound manner (Fig. 3b). This surplus may have to be converted to $\mathrm{N}_{2}$ via nitrification and denitrification process technologies or converted into desired manure nitrogen products, which would allow transport between counties in an economically feasible manner. The mean $\mathrm{NH}_{3}$ emission intensity will exceed the suggested threshold of $31 \mathrm{kgNH}_{3} \mathrm{ha}^{-1}$ in $56 \%$ of counties in the BAU scenario; the $\mathrm{NH}_{3}$ emission intensity threshold is one of the criteria for achieving Sustainable Development Goal $2^{34}$. Around $60 \%$ of China's population will live in regions with $\mathrm{NH}_{3}$ emission intensities higher than $31 \mathrm{kgNH}_{3} \mathrm{ha}^{-1}$ in the BAU scenario in 2050 (Fig. 3e,f).

Impacts of pig relocation and improved technologies. The south-to-north transfer of pigs (SNT) scenario follows the pig 
a

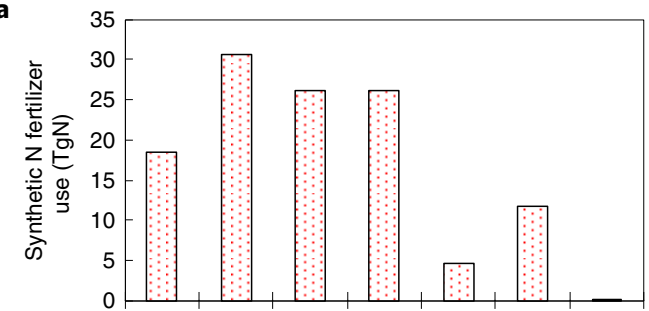

C

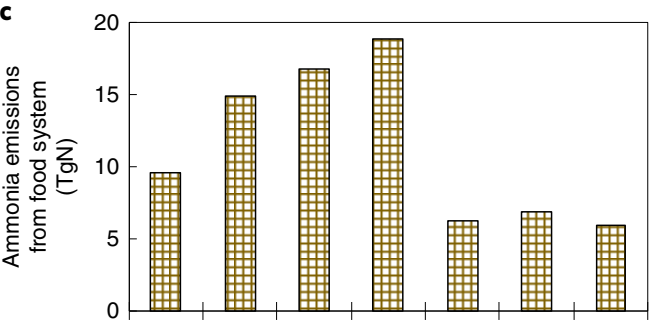

e

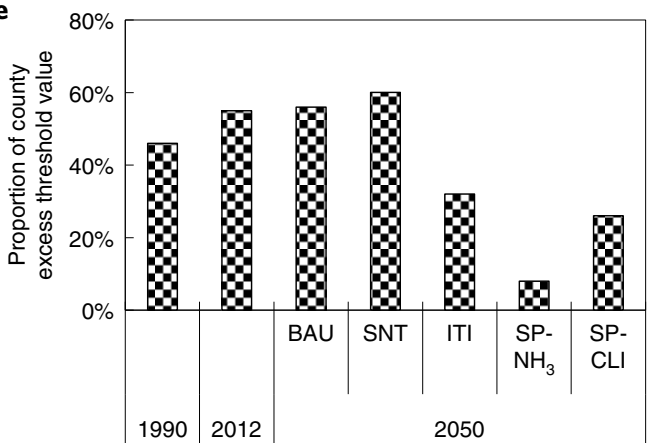

b

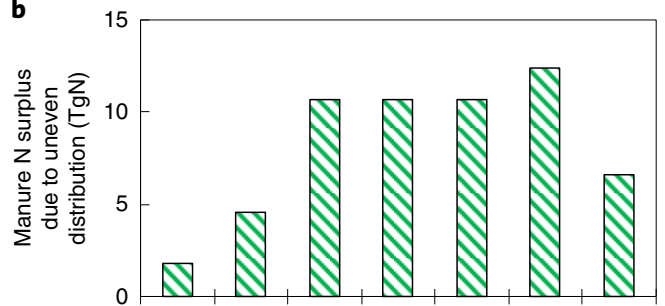

d

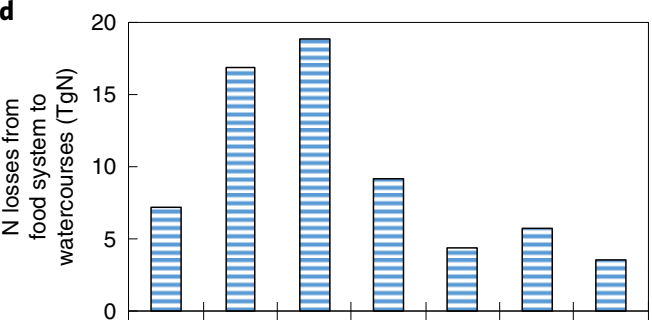

f

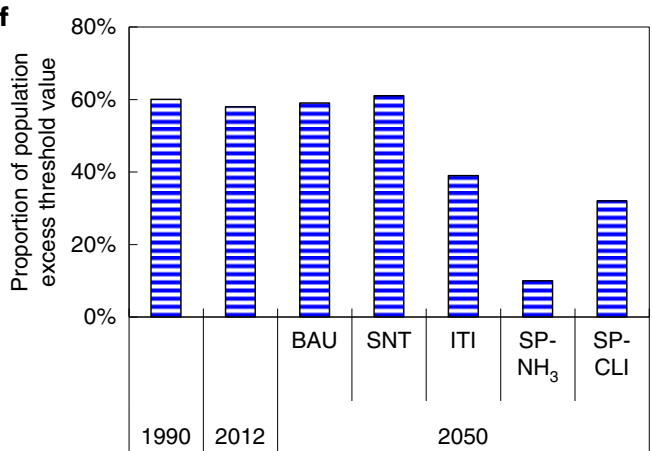

Fig. 3 | Nitrogen use, surplus and loss, and $\mathrm{NH}_{3}$ emissions for various scenarios. $\mathbf{a}$, Total synthetic nitrogen fertilizer use. $\mathbf{b}$, Cumulative manure nitrogen surplus due to uneven distribution of crop and livestock production. $\mathbf{c}$, Total $\mathrm{NH}_{3}$ emissions. d, Total nitrogen losses from the whole food system to watercourses. e, The percentage of counties exceeding the $\mathrm{UN}$-recommended $\mathrm{NH}_{3}$ emission intensity threshold value (31 kgNH$-\mathrm{N}_{3}$ per hectare of agricultural land). f, The percentage of people living in these counties. Manure nitrogen surplus is defined as the difference between total manure nitrogen excretion and total crop nitrogen demand, corrected for the supply of nitrogen by soil, crop residues, wastes, biological $\mathrm{N}_{2}$ fixation and atmospheric deposition (thus without synthetic fertilizer nitrogen), at county level (see equation (3)). Values are given for 1990,2012 and for four different scenarios (BAU, SNT, ITI, SP-NH 3 and S-CLI) in 2050.

relocation policy of the national government as proposed in 2017; it will reduce nitrogen losses to water bodies by $52 \%$ when compared to the BAU scenario due to the transfer of pigs from the watercourse-dense south to the semi-arid north. However, $\mathrm{NH}_{3}$ emissions will increase by $13 \%$ in the SNT scenario compared to $\mathrm{BAU}$, in part due to a higher manure nitrogen recycling because discharge of manure from intensive livestock farms to watercourses has been banned (Fig. 3 and Extended Data Fig. 5). Much of the increase of the $\mathrm{NH}_{3}$ emissions will occur in northern China, where air pollution is most serious (Fig. 4b,e). Thus, the SNT scenario leads to pollution swapping from south to north: swapping water pollution in the south for air pollution in the north ${ }^{35,36}$.

In the integrated technology improvement (ITI) scenario, synthetic fertilizer nitrogen use, $\mathrm{NH}_{3}$ emissions and nitrogen losses to water will reduce by $82 \%, 63 \%$ and $77 \%$, respectively, compared with the BAU scenario (Fig. 3a-d). Evidently, the improved recycling of livestock and human excreta, food waste and crop residues contributed to the substitution of synthetic fertilizers, and reduced nitrogen losses greatly ${ }^{6}$. However, a total of $11 \mathrm{Tg}$ of manure nitrogen could not be effectively recycled due to the geographic separation of crop and livestock production systems in the ITI scenario. In addition, $40 \%$ of the population will still live in counties with $\mathrm{NH}_{3}$ emission intensities higher than the threshold value of $31 \mathrm{kgNH}_{3} \mathrm{ha}^{-1} \mathrm{yr}^{-1}$ (Fig. 3f)
Impacts of livestock spatial planning. Based on optimized spatial planning in the $\mathrm{NH}_{3}$ emission intensity criteria $\left(\mathrm{SP}-\mathrm{NH}_{3}\right)$ scenario, which was developed on top of the ITI scenario, we estimate that some 10 billion animals need to be relocated to be able to achieve a lower $\mathrm{NH}_{3}$ emission intensity for most of the population of China (Extended Data Fig. 6). This number is equivalent to 344 million $\mathrm{LU}$, and includes 484 million pigs, 10 million dairy cattle, 30 million beef cattle, 9,300 million chickens, 146 million sheep and goats, and 1.5 million mules and donkeys (Extended Data Fig. 6). The number accounts for $56 \%$ of the domestic livestock population in the $\mathrm{SP}-\mathrm{NH}_{3}$ scenario, and is equal to the current livestock populations of the United States and the Russian Federation combined ${ }^{30}$. Livestock need to be transferred mainly from southern and eastern China to north and southwest China (Extended Data Fig. 6). About $15 \%$ of the livestock need to be relocated within provincial borders, mainly to shorten the transportation distance to ensure the stability of food supply and reduce transportation costs (Extended Data Fig. 7).

In the $\mathrm{SP}-\mathrm{NH}_{3}$ scenario, total $\mathrm{NH}_{3}$ emissions to air and nitrogen losses to water bodies will decrease by $60-70 \%$ compared with the BAU scenario. However, the $\mathrm{SP}-\mathrm{NH}_{3}$ scenario had slightly higher total $\mathrm{NH}_{3}$ emissions to air and total nitrogen losses to water bodies than the ITI scenario (Fig. 3c,d). However, the SP-NH${ }_{3}$ scenario decreased the proportion of people in counties with exposure to 

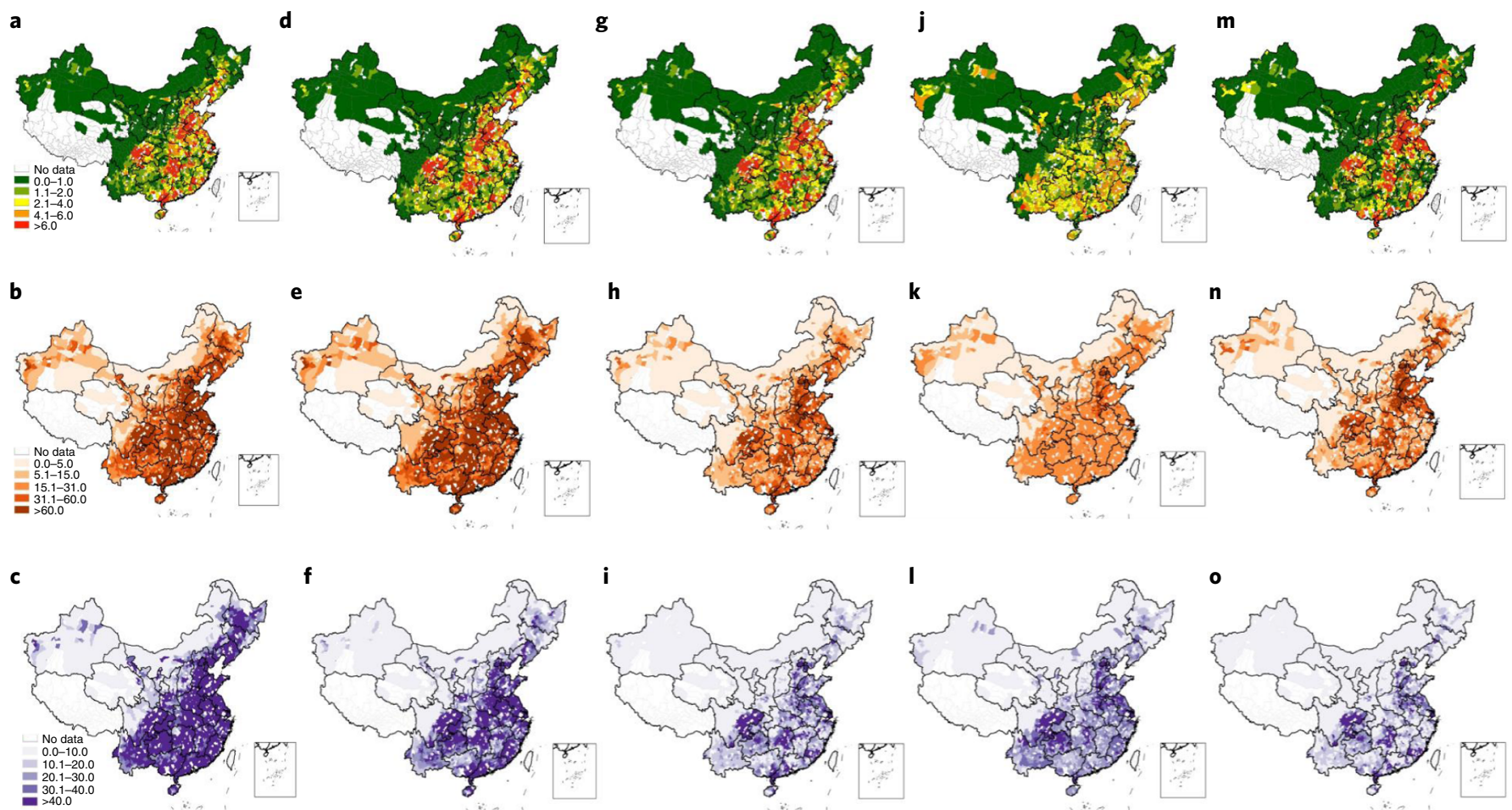

Fig. 4 | Livestock density, $\mathbf{N H}_{3}$ emission intensity and nitrogen losses to watercourses in $\mathbf{2 0 5 0}$ for five scenarios. a-o, Livestock density (LU ha ${ }^{-1}$ ) $(\mathbf{a}, \mathbf{d}, \mathbf{g}, \mathbf{j}, \mathbf{m})$, average $\mathrm{NH}_{3}$ emission intensity $\left(\mathrm{kgNH}_{3}-\mathrm{Nha}^{-1}\right)(\mathbf{b}, \mathbf{e}, \mathbf{h}, \mathbf{k}, \mathbf{n})$ and average nitrogen losses to watercourses $\left(\mathrm{kgNha}^{-1}\right)(\mathbf{c}, \mathbf{f}, \mathbf{i}, \mathbf{l}, \mathbf{o})$ in 2050 for five scenarios: BAU (a-c), SNT (d-f), ITI (g-i), SP-NH $3(\mathbf{j}-\mathbf{I})$ and SP-CLI (m-o).

$\mathrm{NH}_{3}$ emissions higher than the threshold value compared with the BAU and ITI scenarios (Fig. 3e,f). Regions exceeding the $\mathrm{NH}_{3}$ emission intensity threshold value were mainly found in semi-arid intensive cropping areas, that is, mainly in the North China Plain (Fig. 4k). Manure nitrogen surplus and synthetic nitrogen fertilizer use were higher in the SP-NH $\mathrm{NH}_{3}$ than in the ITI scenario (Fig. 3a,b). This is counter to the objective to decrease manure nitrogen surplus and fertilizer nitrogen use through improved manure nitrogen recycling. Evidently, there is a trade-off here between keeping the $\mathrm{NH}_{3}$ emission intensity below the threshold value and bringing livestock production more closely to cropland.

Spatial planning according to crop-livestock integration criteria (SP-CLI), which was also developed on top of the ITI scenario, indicated the need to relocate 5.0 billion animals or 177 million LU, including 170 million pigs, 6.5 million dairy cattle, 31 million beef cattle, 4,323 million chickens, 146 million sheep and goats, and 2.6 million mules and donkeys (Extended Data Fig. 8). The number of relocated animals will be $50 \%$ less than in the $\mathrm{SP}-\mathrm{NH}_{3}$ scenario, and $27 \%$ of the animals had to be relocated over relatively short distances in the SP-CLI scenario (Extended Data Fig. 7). The SP-CLI scenario resulted in $13 \%$ less $\mathrm{NH}_{3}$ emission, $40 \%$ lower nitrogen losses to water bodies, $99 \%$ less nitrogen fertilizer use and $47 \%$ less manure nitrogen wastage compared to the $\mathrm{SP}-\mathrm{NH}_{3}$ scenario (Fig. 3a-d). However, $6.6 \mathrm{Tg}$ of manure nitrogen was still not recycled because the local manure nitrogen supply exceeded the local nitrogen demand by the cropland, which could be reduced through importing more livestock products from global markets. The SP-CLI scenario led to a different geo-relocation of livestock production than the SP-NH $\mathrm{N}_{3}$ scenario (Extended Data Fig. 9). The SP-CLI scenario showed a stronger performance in reducing total nitrogen losses, but a weaker performance in reducing the percentage of the population exposed to a high $\mathrm{NH}_{3}$ emission intensity compared to the $\mathrm{SP}-\mathrm{NH}_{3}$ scenario (Fig. 3f). Evidently, there was a trade-off between keeping the $\mathrm{NH}_{3}$ emission intensity below the threshold value and reducing total nitrogen losses.

\section{Discussion}

Instruments to handle regional manure surpluses. Concentrations of livestock production are found in several regions of the world, mostly in areas with concentrations of humans, that is, near urban $\operatorname{areas}^{37}$, but there are also concentrations of livestock amidst extensive areas of cropland, that is, in large confined animal feeding operations, for example, in North and Latin America ${ }^{38}$. Despite all regulatory measures and economic and voluntary incentives, concentrations of livestock remain persistent hotspots of $\mathrm{NH}_{3}$ emissions and of nutrient losses to groundwater and surface waters. The benefits of a possible relocation of livestock from West European countries to Central European countries have been explored through simulation modelling only ${ }^{39,40}$. The Netherlands government is considering a buy-out of intensive livestock farms near nature conservation areas ${ }^{41}$. However, the number of animals considered in these options and plans is very modest compared to the south-to-north relocation of pig production in China ${ }^{35,36}$ and those of the current study (for example, Fig. 4).

China is a country where spatial relocation of large-scale livestock production could probably be successful because of its large livestock concentrations and its strong central governance. However, spatial planning of livestock production requires clear criteria, principles and procedures (Fig. 5). China started a top-down spatial planning of livestock production in 2014, and has relocated millions of pig farms from regions in the southeast with a dense network of watercourses to north China to reduce water pollution $^{35,36,42}$. As a result, large spatial changes in livestock density have been observed between 2012 and 2017; livestock density was reduced in the south and increased in the north (Extended Data Fig. 10). However, the combination of water protection policies and 


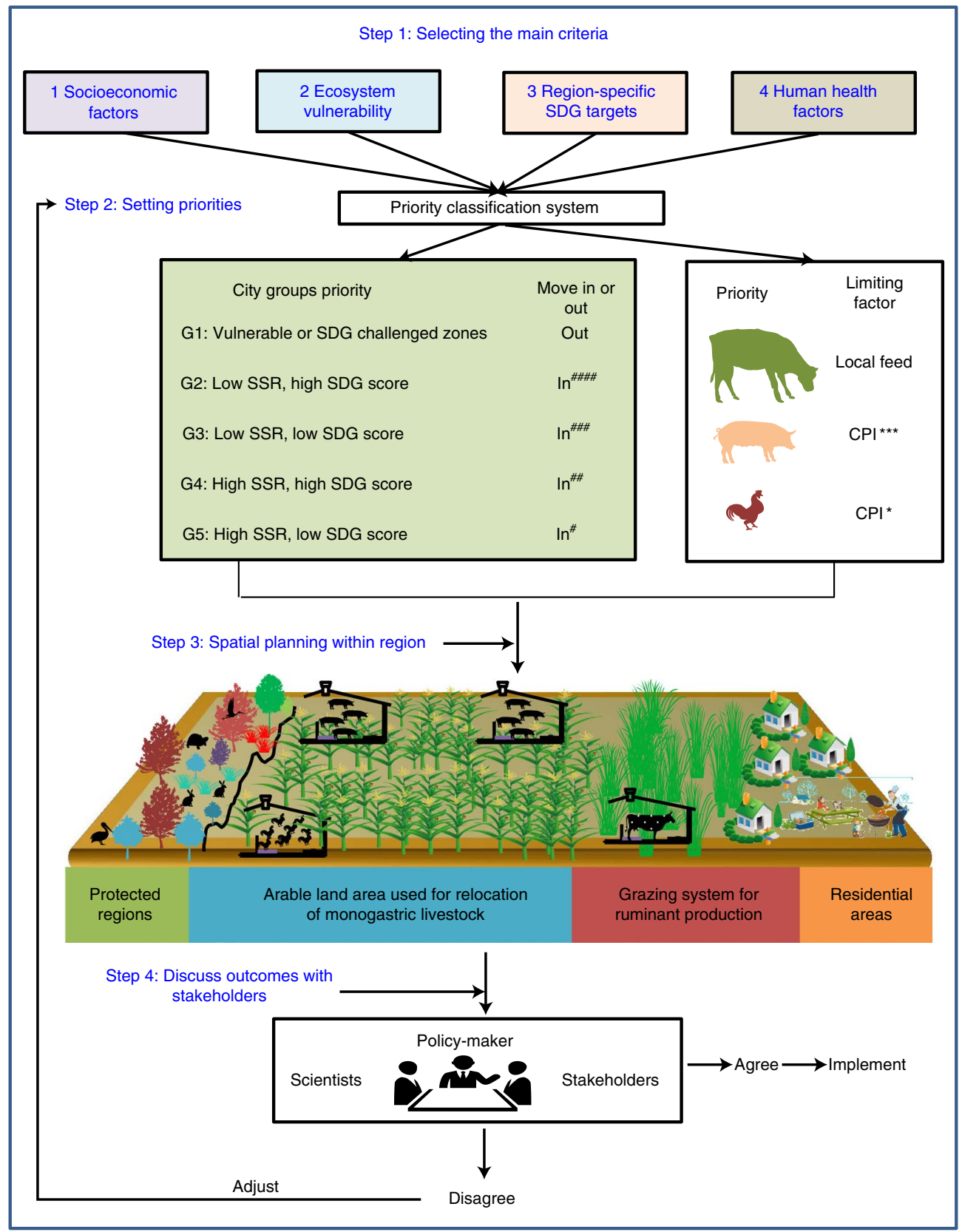

Fig. 5 | Suggested scheme for selecting criteria, setting priorities and optimizing the spatial planning of livestock production in cities and counties in China. \# Represents the priority of city groups for move in livestock; * represents the sensitivity to CPI. CPI, consumer price index; G1-G5, city groups 1-5; SDG; Sustainable Development Goal; SSR, self-sufficient rate.

the pig relocation policy has led to unexpected effects on pork prices which have been enhanced after the outbreak of African swine fever in 2018-2019 and the COVID-19 pandemic in 2020-2021 ${ }^{42}$. As a result, the central government has abandoned the pig relocation plan and given higher priority to the Vegetable and Basket Policy ${ }^{42}$. As a result, major new pig farms were recently built in high $\mathrm{NH}_{3}$ emission intensity regions and high population density regions (Extended Data Fig. 10).

Minimizing trade-offs of livestock spatial planning. Spatial planning can be successful in protecting ecosystems when sound ecological and social-economic principles are applied together ${ }^{43}$. The Vegetable and Basket Policy ${ }^{44,45}$ may be seen as a one-sided spatial planning approach aimed at increasing vegetable and meat production and its fast delivery to urban consumers. The south-to-north relocation of pig production ${ }^{35,36,42}$ may be seen as a one-sided spatial planning approach aimed at decreasing surface water pollution. It is clear that these two spatial planning policies have large side-effects.

Serious trade-offs are also observed in the two spatial planning scenarios of our study. Spatial relocation of livestock to reduce the exposure of humans to high $\mathrm{NH}_{3}$ emissions is not effective in enhancing manure nitrogen recycling and reducing synthetic nitrogen fertilizer use in China. In contrast, spatial relocation of livestock aimed at enhancing manure nitrogen recycling and reducing synthetic nitrogen fertilizer use is not effective in reducing the exposure of humans to high $\mathrm{NH}_{3}$ emissions. These results are caused in part by the fact that intensive crop production systems in China already 
have a high $\mathrm{NH}_{3}$ emission intensity due to the liberal use of urea fertilizers (Fig. 3).

Pollution swapping through relocation of livestock production can be minimized through the implementation of strict emission mitigation measures in crop and livestock production systems. For example, urea-based nitrogen fertilizers have to be deeply placed/ injected into the soil or have to be replaced by nitrate-based fertilizers to reduce $\mathrm{NH}_{3}$ emissions ${ }^{46-48}$. Similarly, low-protein animal feeding and low-emission manure storage and application to cropland may greatly decrease $\mathrm{NH}_{3}$ emissions associated with manure application. Implementing low-emission technology and balanced fertilization before any spatial planning action greatly reduces the risk of pollution swapping but also decreases the benefits (and costs) of these actions. An optimum balance needs to be found between the cost and benefits of low-emission technology and the costs and benefits of spatial planning actions, without compromising agricultural productivity. People in rural and peri-urban areas will ultimately benefit from cleaner air and water because of the substantial reductions in $\mathrm{NH}_{3}$ emission and related health costs, but we cannot exclude that food production costs will increase ${ }^{48}$.

Sensitivity and implication of livestock spatial planning. Spatial planning of livestock production under $\mathrm{NH}_{3}$ emission control criteria was highly sensitive to the selection of the threshold value. The stricter the threshold value, the higher the number of livestock that need to be relocated within China. The threshold value was set at $31 \mathrm{kgNH}_{3} \mathrm{ha}^{-1}$ - the criteria for achieving Sustainable Development Goal 2-for sustainable and resilient food production systems ${ }^{34}$. The criteria will be stricter in many European countries by 2030 because the National Emission Ceiling Directive has implemented regulations on total $\mathrm{NH}_{3}$ emissions per country ${ }^{49}$. China will have to relocate more animals when the threshold value decreases to below $31 \mathrm{kgNH}_{3} \mathrm{ha}^{-1}$, or will have to further cut domestic livestock production either through dietary changes to reduce meat consumption or through import of more livestock products from the global market. Spatial planning of livestock production under crop-livestock integration criteria was sensitive to the bioavailability of nitrogen from different organic resources. Fewer animals will need to be relocated if the bioavailability of nitrogen is considered because there is a lower surplus of bioavailable manure nitrogen than of total manure nitrogen (Fig. 3b and Extended Data Fig. 5b). Urbanization may also play a role in shaping the relocation of animals: urbanization leads to fewer people in the countryside and hence to fewer people exposed to cropland and livestock production related $\mathrm{NH}_{3}$ emissions s. $^{50}$.

Other possible pollutants, such as heavy metals, veterinary antibiotics and greenhouse gas emissions, were not considered in this study but may have large impacts as well. This suggests that additional indicators and ecosystem threshold values have to be considered in spatial planning (Fig. 5). Current barriers for proper manure treatment and recycling to cropland need to be fully removed to be able to recouple crop and livestock production systems effectively ${ }^{51,52}$. The strive for carbon neutrality will also have implications for the optimal locations of production and consumption centres.

Overall, China may have to relocate 5-10 billion animals to tackle nitrogen pollution of air and water caused by concentrations of livestock production. This is an enormous challenge, with huge economic and societal impacts, but will yield improved nitrogen pollution control as final result. Policy-makers need to carefully select the criteria for spatial planning of livestock production because the ultimate effects of spatial planning depend on the criteria prioritized.

\section{Methods}

The NUFER model was used to quantify the environmental impacts of different spatial distributions of crop and livestock production at county level in China ${ }^{13}$.
NUFER includes data for 2,300 counties (out of 2,850 counties), which accounted for $94 \%$ of the total crop production and for $98 \%$ of the total livestock production in China in $2012^{6,28,53}$. NUFER calculates the $\mathrm{NH}_{3}$ emissions and nitrogen losses to watercourses from the whole food production and consumption chain. These results allow us to quantify the relationship between livestock density and nitrogen losses to air and watercourses at county level. NUFER also provides information about fertilizer nitrogen use and total nitrogen flows per county; the nitrogen surplus includes all nitrogen losses to the environment and possible changes of soil nitrogen sequestration. For more information, see ref. ${ }^{13}$

Geographic distribution of livestock production. The geographic distribution of livestock production was characterized by the livestock density per county and the ratio of manure nitrogen excretion and crop nitrogen uptake per county. County-level animal numbers were derived from ref. ${ }^{13}$, which originally came from county, city and provincial level statistical data (census data). Numbers of animals in different livestock categories were converted to LU.

Livestock density was calculated as follows:

$$
\text { livestock density }=\mathrm{LU} \div \text { agricultural land area }
$$

where livestock density is the livestock density per county $\left(\mathrm{LU} \mathrm{ha}^{-1}\right), \mathrm{LU}$ is the total number of LUs per county, and agricultural land area is the total agricultural land area per county (ha).

The geographic (dis)connection between crop and livestock production was characterized by combinations of manure nitrogen excretion, synthetic fertilizer nitrogen input and crop nitrogen uptake per county. Two ratios have been used: (1) ratio of manure nitrogen excretion to harvested crop nitrogen uptake; (2) ratio of synthetic fertilizer nitrogen input to harvested crop nitrogen uptake. Data were derived from ref. ${ }^{13}$, and include county-level data for 1990 and 2012. For comparison, we used also data from United States for 1990 and 2012; these were reproduced from the Net Anthropogenic Nitrogen Inputs (NANI) toolbox ${ }^{21}$.

Estimates of nitrogen requirements for crop production. Total nitrogen requirement for crop production per county was calculated as follows:

$$
\mathrm{Ic}_{\mathrm{N} \text { requirement }}=\sum_{i=1}^{n}\left[\left(\mathrm{Oc}_{\text {main product }, i}+\mathrm{Oc}_{\text {straw }, i}\right)\right] \times \mathrm{Uf}(i)+\mathrm{Oc}_{\text {managed grass }} \times \mathrm{Uf}
$$

where $\mathrm{Ic}_{\mathrm{N}}$ requirement is the nitrogen requirement per county for crop production under balanced fertilization criteria, that is, when nitrogen application is equal to crop nitrogen demand; $\mathrm{Oc}_{\text {main product, } i}$ and $\mathrm{Oc}_{\text {straw }, i}$ are the amounts of nitrogen in the main crop product and in straw at harvest per county, respectively $(\mathrm{kgN})$; and $\mathrm{Oc}_{\text {managed grass }}$ is the amount of nitrogen in harvested grass from managed grassland per county $(\mathrm{kgN})$. These values were corrected by the uptake factors $(\mathrm{Uf}(i))$ of each crop species under balanced fertilization (Extended Data Table 2).

We assumed that there is transport of manure within counties and no transport of manure between counties because of the high cost of long-distance transport. Further, we assumed substantial improvements of nutrient management in the whole food system by 2050 , including a reduction in $\mathrm{NH}_{3}$ emissions from the manure management chain by $60 \%$, a ban on the discharge of manure to watercourses and to landfills, and enhanced collection, sanitation and utilization of nitrogen in food waste and human excreta ${ }^{6}$

The nitrogen balance was calculated per county as follows:

$$
\begin{aligned}
\mathrm{I} c_{\text {manure } \mathrm{N} \text { surplus }}= & \mathrm{I} \mathrm{c}_{\mathrm{N} \text { requirement }}-\mathrm{I} \mathrm{c}_{\text {deposition }}-\mathrm{I} \mathrm{c}_{\mathrm{BNF}}-\mathrm{I} \mathrm{c}_{\text {irrigation }} \\
& -\mathrm{I} \mathrm{c}_{\text {straw to field }}-\mathrm{I} \mathrm{c}_{\text {manure to field }}-\mathrm{Ic}_{\text {food by-product }} \\
& -\mathrm{I} \mathrm{c}_{\text {human manure }}-\mathrm{Ic}_{\text {soil mineralization }}
\end{aligned}
$$

where $\mathrm{Ic}_{\text {manure } \mathrm{N} \text { surplus }}$ is the difference between nitrogen demand and nitrogen supply per county (excluding synthetic nitrogen fertilizer), defined as manure nitrogen surplus: a negative value of $\mathrm{Ic}_{\mathrm{N} \text { surplus }}$ indicates an oversupply of nitrogen; a positive value of $\mathrm{Ic}_{\mathrm{N} \text { surplus }}$ indicates a relative shortage of nitrogen. Then, all the negative values were added together, to evaluate the cumulative effects. I $\mathrm{c}_{\text {deposition }}, \mathrm{Ic}_{\mathrm{BNF}}$ and $\mathrm{Ic}_{\text {irrigation }}$ are the nitrogen inputs via atmospheric nitrogen deposition, biological $\mathrm{N}_{2}$ fixation $(\mathrm{BNF})$ and irrigation water per county. $\mathrm{Ic}_{\text {straw to field }}, \mathrm{Ic}_{\text {manure to field }}, \mathrm{Ic}_{\text {food by-product }}$ and $\mathrm{Ic}_{\mathrm{human} \text { manure }}$ are nitrogen inputs via organic resources per county, that is, crop straw, animal manure, food and kitchen waste, and human excreta. $\mathrm{Ic}_{\text {soil mineralization }}$ is the nitrogen supply from net soil mineralization.

Scenarios for 2050. BAU scenario. This scenario follows the SSP2 storyline towards $2050^{28}$. China's total demand for agricultural products, including food, feed and biofuel, is projected to increase by $25 \%$ in per-capita calorie demand in 2050 relative to 2010 in the BAU scenario. Per-capita demand for animal-source calories is projected to increase almost twice as fast as for total calories compared with 2010. The total projected food demand and production in China are listed in Extended Data Table 2. The increase in food production by 2050 was evenly allocated to each county according to their shares in the total in 2012. 
SNT scenario. This scenario specifically deals with pig production, which is by far the main livestock species in China. It follows the BAU scenario but uses a different geographic distribution of pig production and includes a ban on the discharge of manure to watercourses, following the Ten Water Protection Action. The Ministry of Agricultural and Rural Affairs categorized provinces into four zones in 2017 according to their vulnerability to surface water pollution and their potential for pig production: (1) potential development zones, (2) key development zones, (3) moderate development zones and (4) constrained development zones ${ }^{35}$. We assumed that the annual increase of pig production in potential development zones was two times higher than that in key development zones, and four times higher than that in the moderate development zones. There was no increase of pig production in the constrained development zones. These assumptions allowed us to calculate the total pig production for different pig production zones in 2050 (Supplementary Information).

ITI scenario. This scenario was developed to supplement the BAU scenario, but with substantial technological improvements in nutrient management throughout the whole food system. The technologies were specific for three sectors, that is, crop production, livestock manure management chain, and food waste and human excreta. The technologies aimed to reduce $\mathrm{NH}_{3}$ emissions and to increase the recycling of manure and human excreta, and food waste. Details about the key technologies and potential effects on nitrogen recycling and $\mathrm{NH}_{3}$ emission reduction are presented in the Supplementary Information.

SP scenarios. These scenarios were developed to supplement the ITI scenario, but with comprehensive spatial planning of livestock production (Fig. 5). Two contrasting variants were developed: (1) to reduce the exposure of most people to below the United Nations threshold for the $\mathrm{NH}_{3}$ emission intensity $\left(\mathrm{SP}-\mathrm{NH}_{3}\right.$ ); (2) to optimize the coupling of crop-livestock production in terms of nitrogen requirement and supply (SP-CLI). Detailed descriptions of the procedures for livestock spatial planning under these two scenarios are described in the Supplementary Information.

Statistics and reproducibility. No statistical methods were used to predetermine sample size.

Reporting Summary. Further information on research design is available in the Nature Research Reporting Summary linked to this article.

\section{Data and materials availability}

All data needed to evaluate the conclusions in the paper are present in the paper and/or the Supplementary Materials.

Received: 19 August 2021; Accepted: 20 December 2021; Published online: 10 February 2022

\section{References}

1. Wu, Y. et al. $\mathrm{PM}_{2.5}$ pollution is substantially affected by ammonia emissions in China. Environ. Pollut. 218, 86-94 (2016).

2. Liu, M. et al. Ammonia emission control in China would mitigate haze pollution and nitrogen deposition, but worsen acid rain. Proc. Natl Acad. Sci. USA 116, 7760-7765 (2019).

3. $\mathrm{Yu}, \mathrm{C}$. et al. Managing nitrogen to restore water quality in China. Nature 567, 516-520 (2019).

4. $\mathrm{Gu}, \mathrm{B}$. et al. Integrated reactive nitrogen budgets and future trends in China. Proc. Natl Acad. Sci. USA 112, 8792-8797 (2015).

5. Bai, Z. et al. China's livestock transition: driving forces, impacts, and consequences. Sci. Adv. 4, eaar8534 (2018).

6. Jin, X. et al. Spatial planning needed to drastically reduce nitrogen and phosphorus surpluses in China's agriculture. Environ. Sci. Technol. 4, 11894-11904 (2020)

7. Jin, S. et al. Decoupling livestock and crop production at the household level in China. Nat. Sustain. 4, 48-55 (2021).

8. Zhang, C. et al. Rebuilding the linkage between livestock and cropland to mitigate agricultural pollution in China. Resour. Conserv. Recycl. 144, 65-73 (2019).

9. Gerber, P. et al. Geographical determinants and environmental implications of livestock production intensification in Asia. Bioresour. Technol. 96 , 263-276 (2005).

10. Wei, S. et al. Environmental, economic and social analysis of peri-urban pig production. J. Cleaner Prod. 129, 596-607 (2016).

11. Uwizeye, A. et al. Nitrogen emissions along global livestock supply chains. Nat. Food 1, 437-446 (2020).

12. Bai, Z. et al. Nitrogen, phosphorus, and potassium flows through the manure management chain in China. Environ. Sci. Technol. 24, 13409-13418 (2016).

13. Wang, M. et al. Hotspots for nitrogen and phosphorus losses from food production in China: a county-scale analysis. Environ. Sci. Technol. 52, 5782-5791 (2018)
14. Lassaletta, L. et al. Future global pig production systems according to the Shared Socioeconomic Pathways. Sci. Total Environ. 665, 739-751 (2019).

15. Ma, L. et al. Exploring future food provision scenarios for China. Environ. Sci. Technol. 53, 1385-1393 (2019).

16. $\mathrm{Hu}$, Y. et al. Food production in China requires intensified measures to be consistent with national and provincial environmental boundaries. Nat Food 1, 572-582 (2020)

17. Bradford, M. A., Fierer, N. \& Reynolds, J. F. Soil carbon stocks in experimental mesocosms are dependent on the rate of labile carbon, nitrogen and phosphorus inputs to soils. Funct. Ecol. 22, 964-974 (2008).

18. Reijnders, L. Phosphorus resources, their depletion and conservation, a review. Resour. Conserv. Recycl. 93, 32-49 (2014).

19. Liu, Q. et al. Global animal production and nitrogen and phosphorus flows. Soil Res. 55, 451-462 (2017)

20. Willems, J. et al. Why Danish pig farms have far more land and pigs than Dutch farms? Implications for feed supply, manure recycling and production costs. Agric. Syst. 144, 122-132 (2016).

21. Swaney, D. P., Howarth, R. W. \& Hong, B. County, subregional and regional nitrogen data derived from the Net Anthropogenic Nitrogen Inputs (NANI) toolbox. Data Brief 18, 1877-1888 (2018).

22. Delgado, C. L. et al. Determinants and Implications of the Growing Scale of Livestock Farms in Four Fast-Growing Developing Countries Report No. 157 (International Food Policy Research Institute, 2008).

23. Steinfeld, H. et al. Livestock in a Changing Landscape, vol. 1: Drivers, Consequences, and Responses (Island Press, 2013).

24. Błażejczyk-Majka, L. \& Radosław, K. A. L. A. Concentration and productivity of livestock and mixed farms in new and old EU member states. A regional level approach. J. Cent. Eur. Agric. 16, 159-176 (2015).

25. Drabenstott, M., Henry, M. \& Mitchell, K. Where have all the packing plants gone? The new meat geography in rural America. Economet. Rev. 84, 65-82 (1999).

26. Donham, K. J. The concentration of swine production: effects on swine health, productivity, human health, and the environment. Vet. Clin. North Am. Food Anim. Pract. 16, 559-597 (2000).

27. Li, T. et al. All-cause mortality risk associated with long-term exposure to ambient $\mathrm{PM}_{25}$ in China: a cohort study. Lancet Public Health 3, e470-e477 (2018)

28. Zhao, H. et al. China's future food demand and its implications for trade and environment. Nat. Sustain. 4, 1042-1051 (2021).

29. The Zero Increase of Fertilizer and Pesticides Action (Ministry of Agricultural and Rural Affairs, 2015); http://www.moa.gov.cn/nybgb/2015/san/201711/ t20171129_5923401.htm

30. Statistical Databases (FAO, 2021); http://www.fao.org/faostat/en/

31. Chen, X. et al. Producing more grain with lower environmental costs. Nature 514, 486-489 (2014)

32. Cui, Z. et al. Pursuing sustainable productivity with millions of smallholder farmers. Nature 555, 363-366 (2018).

33. Chadwick, D. et al. Strategies to reduce nutrient pollution from manure management in China. Front. Agric. Sci. Eng. 7, 45-55 (2020)

34. Sachs, J. et al. Sustainable Development Report 2020: The Sustainable Development Goals and COVID-19 (Cambridge Univ. Press, 2020).

35. Bai, Z. et al. Socio-economic drivers of pig production and their effects on achieving sustainable development goals in China. J. Integr. Environ. Sci. 16, 141-155 (2019a).

36. Bai, Z. et al. China's pig relocation in balance. Nat. Sustain. 2, 888-888 (2019b).

37. Hou, Y., Oenema, O. \& Zhang, F. Integrating crop and livestock production systems-towards agricultural green development. Front. Agric. Sci. Eng. 8, $1-14$ (2021)

38. Franzluebbers, A. et al. Integrated crop-livestock systems: lessons from New York, British Columbia, and the south-eastern United States. Front. Agric. Sci. Eng. 8, 81-96 (2021).

39. Van Grinsven, H. J. et al. Potential of extensification of European agriculture for a more sustainable food system, focusing on nitrogen. Environ. Res. Lett. 10, 025002 (2015).

40. Van Grinsven, H. J. et al. Reducing external costs of nitrogen pollution by relocation of pig production between regions in the European Union. Reg. Environ. Change 18, 2403-2415 (2018).

41. Erisman, J. W. Setting ambitious goals for agriculture to meet environmental targets. One Earth 4, 15-18 (2021).

42. Bai, Z. et al. Impacts of African swine fever on water quality in China. Environ. Res. Lett. 16, 054032 (2021).

43. Foley, M. M. et al. Guiding ecological principles for marine spatial planning. Mar. Policy 34, 955-966 (2010).

44. Li, X. et al. Perspectives on livestock production systems in China. Rangeland J. 30, 211-220 (2008).

45. Wang, H. et al. Producing and procuring horticultural crops with Chinese characteristics: the case of northern China. World Dev. 37, 1791-1801 (2009). 
46. Ti, C. et al. Potential for mitigating global agricultural ammonia emission: a meta-analysis. Environ. Pollut. 245, 141-148 (2019).

47. Sha, Z. et al. Improved soil-crop system management acids in $\mathrm{NH}_{3}$ emission mitigation in China. Environ. Pollut. 289, 117844 (2021).

48. Zhang, X. et al. Societal benefits of halving agricultural ammonia emissions in China far exceed the abatement costs. Nat. Commun. 11, 4357 (2020).

49. Giannakis, E., Kushta, J., Bruggeman, A. \& Lelieveld, J. Costs and benefits of agricultural ammonia emission abatement options for compliance with European air quality regulations. Environ. Sci. Eur. 31, 1-13 (2019).

50. Wang, S. et al. Urbanization can benefit agricultural production with large-scale farming in China. Nat. Food 2, 183-191 (2021).

51. Zhang, T. et al. Replacing synthetic fertilizer by manure requires adjusted technology and incentives: a farm survey across China. Resour. Conserv. Recycl. 168, 105301 (2021).

52. Tan, M. et al. Operational costs and neglect of end-users are the main barriers to improving manure treatment in intensive livestock farms. $J$. Cleaner Prod. 289, 125149 (2021).

53. National Data (National Bureau of Statistics of China); http://www.stats.gov.cn/

\section{Acknowledgements}

This work was supported by the Nature Science Foundation of China (31872403, 32002138, 71961137011, 31801941, 31972517); the Youth Innovation Promotion Association, Chinese Academy of Sciences (2019101); the National Social Science Fund of China (20BZZ040); Key Laboratory of Agricultural Water Resources-CAS (ZD201802); the Outstanding Young Scientists Project of Natural Science Foundation of Hebei (C2019503054); Key R\&D Program of Hebei (21327507D); Hebei Dairy Cattle Innovation Team of Modern Agro-industry Technology Research System
HBCT2018120206. Z.B. thanks the FABLE Consortium, Food and Land Use (FOLU) Coalition and the Norwegian Climate and Forest Initiative (NICFI). This publication contributes to UNCNET, a project funded under the JPI Urban Europe/China collaboration (870234, FFG, Austria).

\section{Author contributions}

All authors contributed equally to the design, implementation, and analysis of this study.

\section{Competing interests}

The authors declare no competing interests.

\section{Additional information}

Extended data are available for this paper at https://doi.org/10.1038/ s43016-021-00453-z.

Supplementary information The online version contains supplementary material available at https://doi.org/10.1038/s43016-021-00453-z.

Correspondence and requests for materials should be addressed to Zhaohai Bai or Lin Ma.

Peer review information Nature Food thanks Xuejun Liu and the other, anonymous, reviewer(s) for their contribution to the peer review of this work.

Reprints and permissions information is available at www.nature.com/reprints.

Publisher's note Springer Nature remains neutral with regard to jurisdictional claims in published maps and institutional affiliations.

(c) The Author(s), under exclusive licence to Springer Nature Limited 2022 

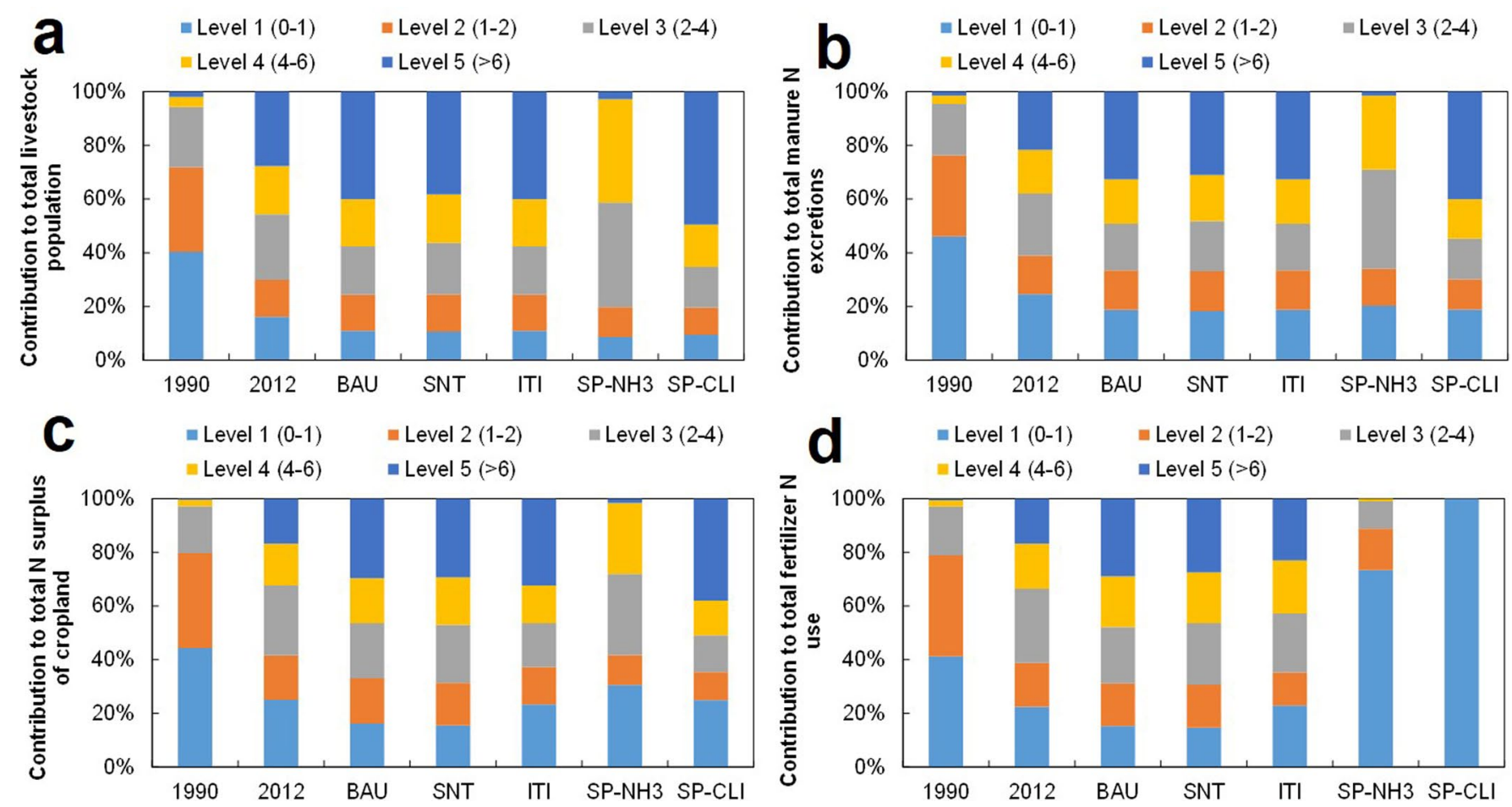

Extended Data Fig. 1 | Contribution of each counties group to total livestock population (a), manure nitrogen (N) excretions, synthetic fertilizer N application (c) and N surplus of cropland (d) according to their livestock density in 1990, 2012 and different scenarios in 2050. Level represents the livestock density, in LU ha-1. Note: BAU is business as usual scenario which follows the SSP2 storyline; SNT, is south to north transfer of pig production scenario; ITI is the integrated technology improvement scenario; SP-NH3 is livestock spatial planning with NH3 criteria scenario; and SP-CLI is livestock spatial planning with crop-livestock integration criteria. 

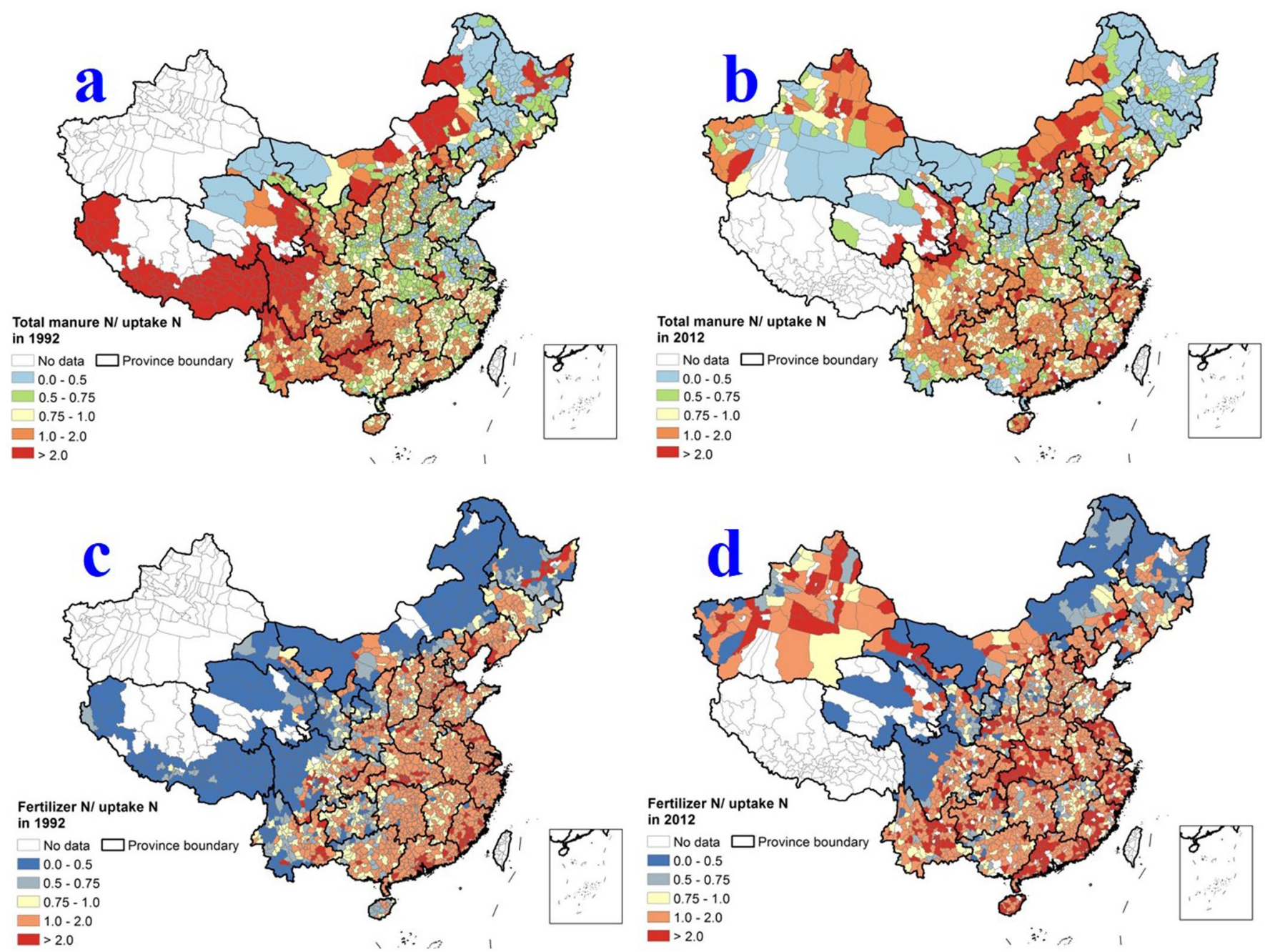

Extended Data Fig. 2 | Ratio of livestock manure N excretions and crop N uptake at county level in 1992 (a) and 2012 (b), and ratio of synthetic fertilizer N input and crop N uptake at county level in 1992 (c) and 2012 (d). 

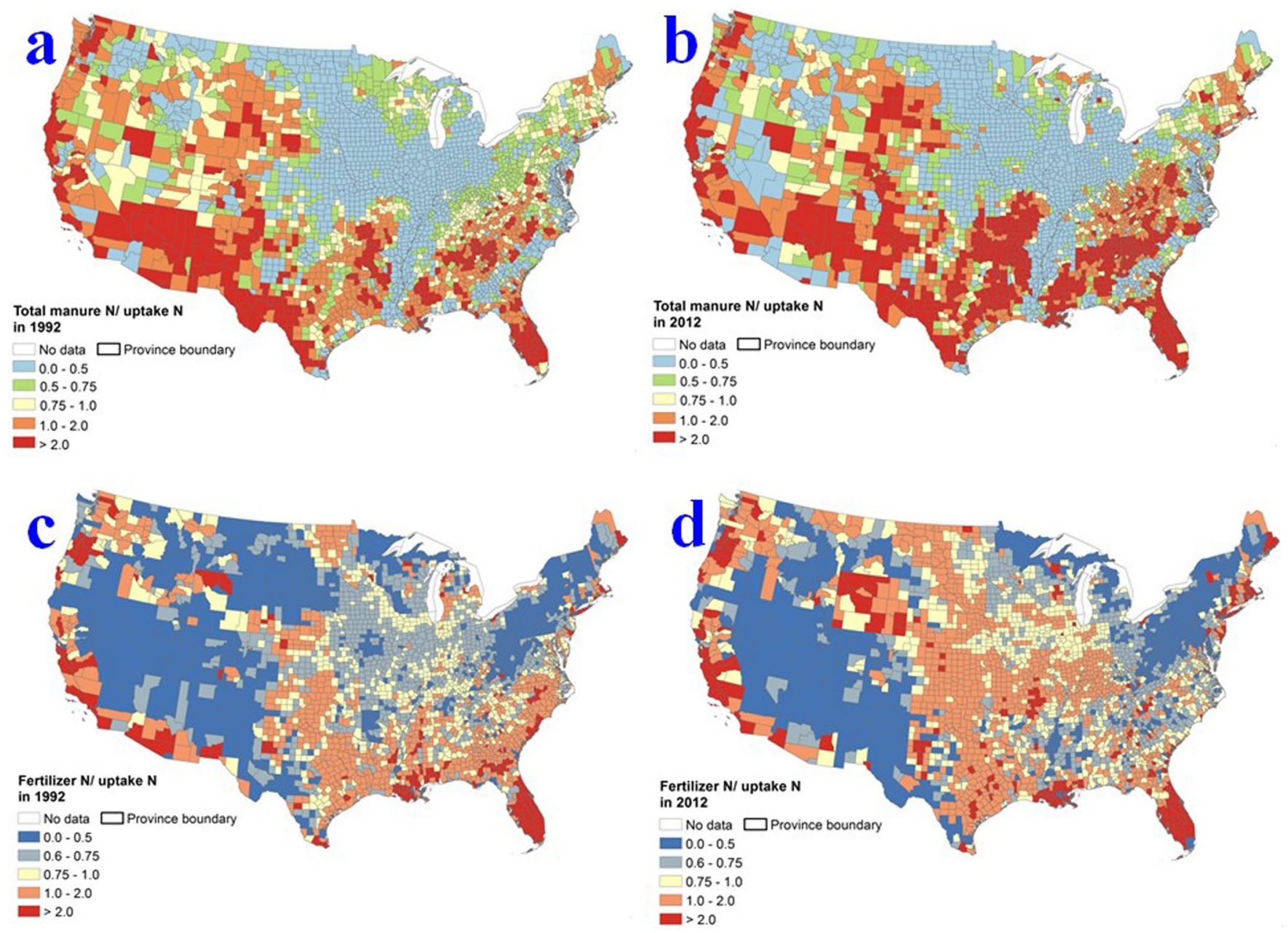

Extended Data Fig. 3 | Mapping the manure N and crop N ratio in United States in 1992 (a) and 2012 (b), and synthetic fertilizer use in 1992 (c) and $2012(d)$. 

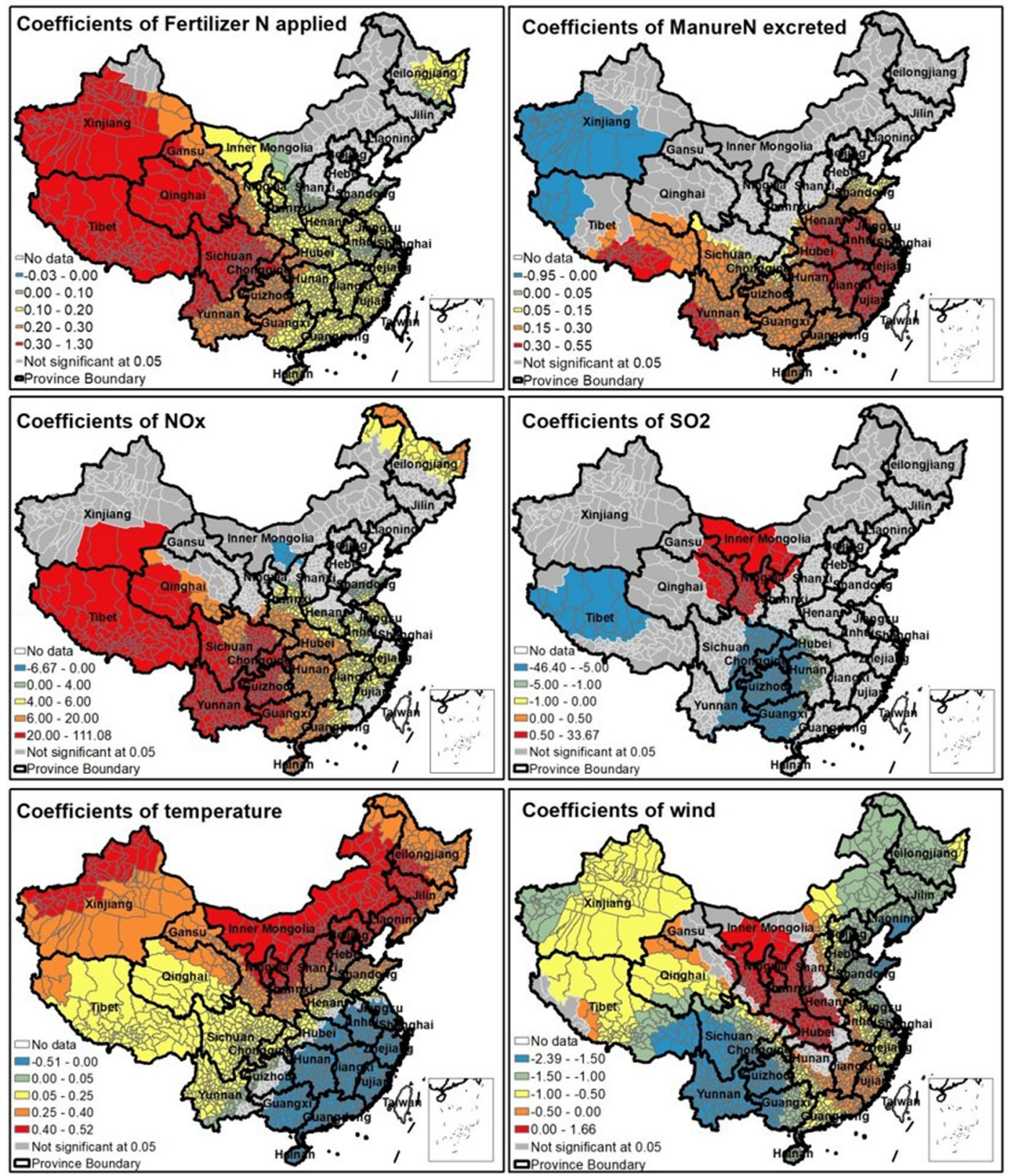

Extended Data Fig. 4 | Spatial distributions of the correlation coefficients of the annual mean $\mathrm{PM}_{2.5}$ concentration in the air and total synthetic fertilizer $\mathrm{N}$ use per county level (a), of the $\mathrm{PM}_{25}$ concentration with total livestock $\mathrm{N}$ excretion (b), with annual mean $\mathrm{NO}_{x}$ concentration in air (c), with annual mean $\mathrm{SO}_{2}$ concentration in air (d), with annual mean air temperature (e) and with annual mean wind speed (f) to in China in 2012. Note: value indicates the slope of simulated correlations (regression coefficients), while the significance was represents by color. 

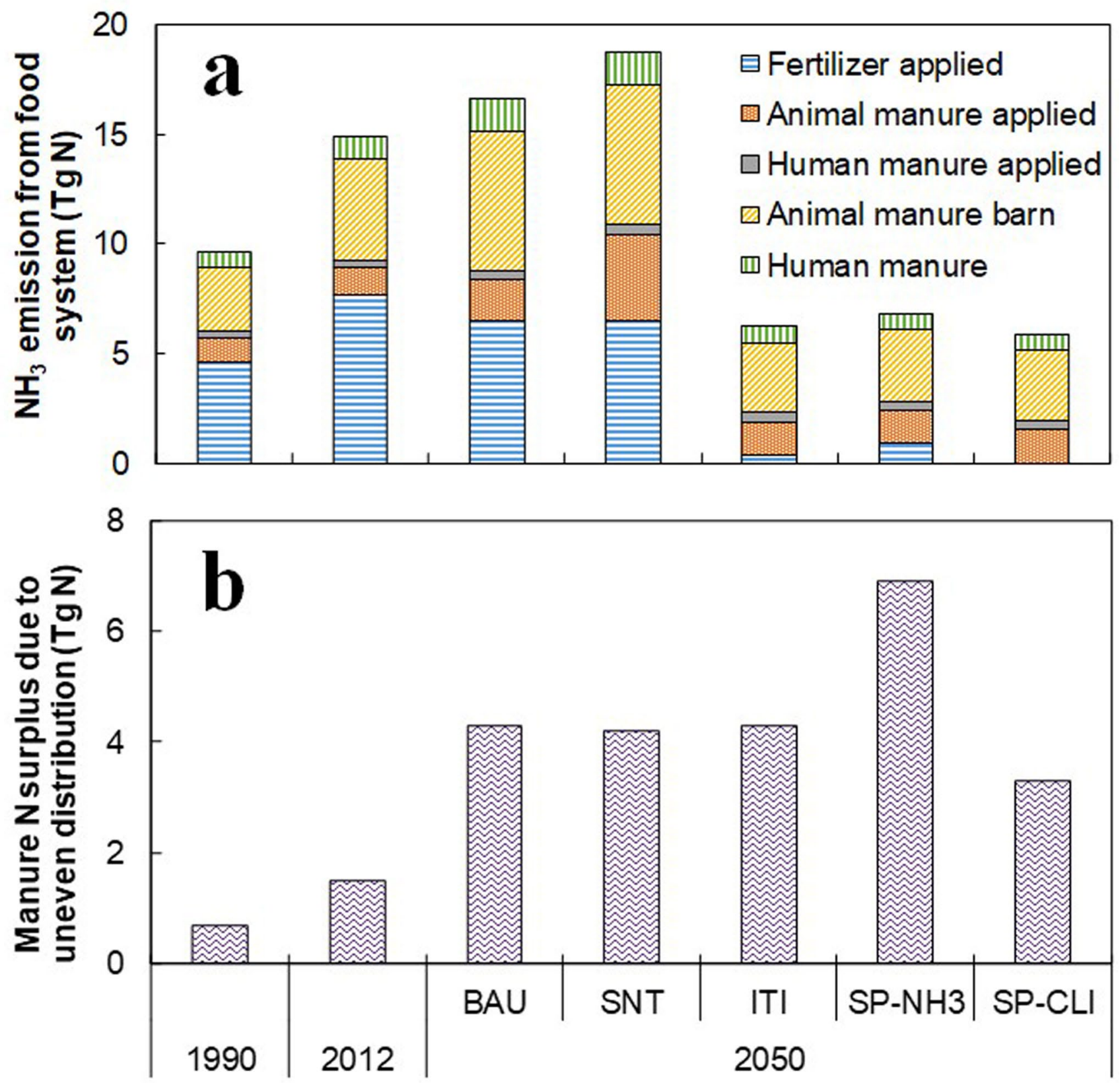

Extended Data Fig. 5 | Ammonia emissions from the food system (a), and manure $\mathbf{N}$ surplus due to uneven distribution of crop-livestock production when considering the bioavailability of manure $\mathrm{N}$ as criterion for estimating the $\mathrm{N}$ surplus in 1990, 2012 and for different scenarios in 2050 . Note: Definition of scenarios see Extended Data Fig. 1. The bioavailability of different organic resources under improved management see Jin et al., 2020. 

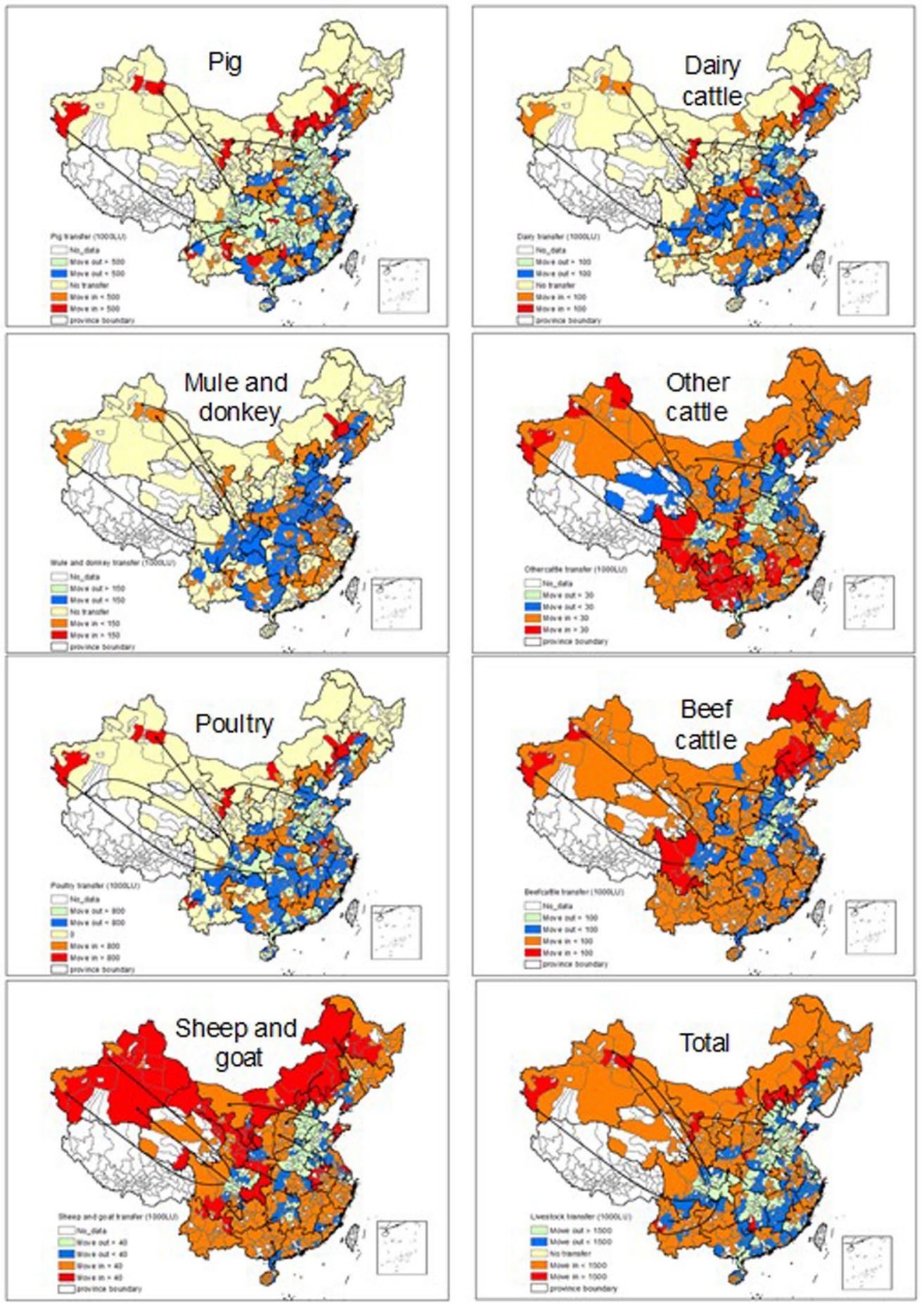

Extended Data Fig. 6 | Illustration of the relocation of livestock following the optimization of livestock spatial planning scenarios - SP-NH in $_{2} 2050$. Arrows indicate the likely movement of animals from southeast to west and northwest, mainly via shutdown farms in the move out regions and build new farms in the move in regions. 

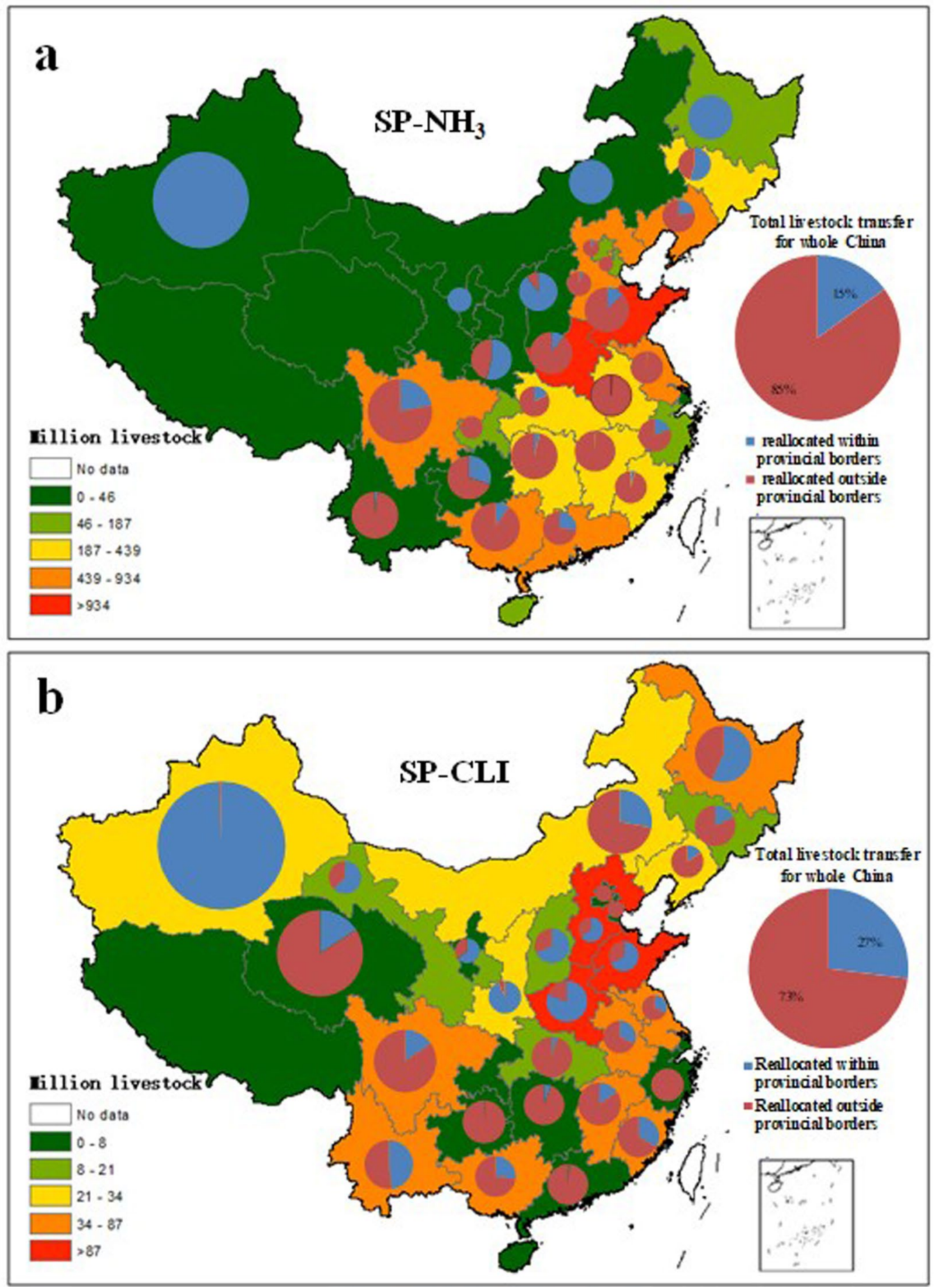

Extended Data Fig. 7 | Illustration of the relocation of livestock following within or outside of the provincial border under the livestock spatial planning scenarios - SP-NH $\mathrm{NH}_{3}$ (a) and SP-CLI (b) in 2050. Note: Definition of scenarios see Extended Data Fig. 1. 

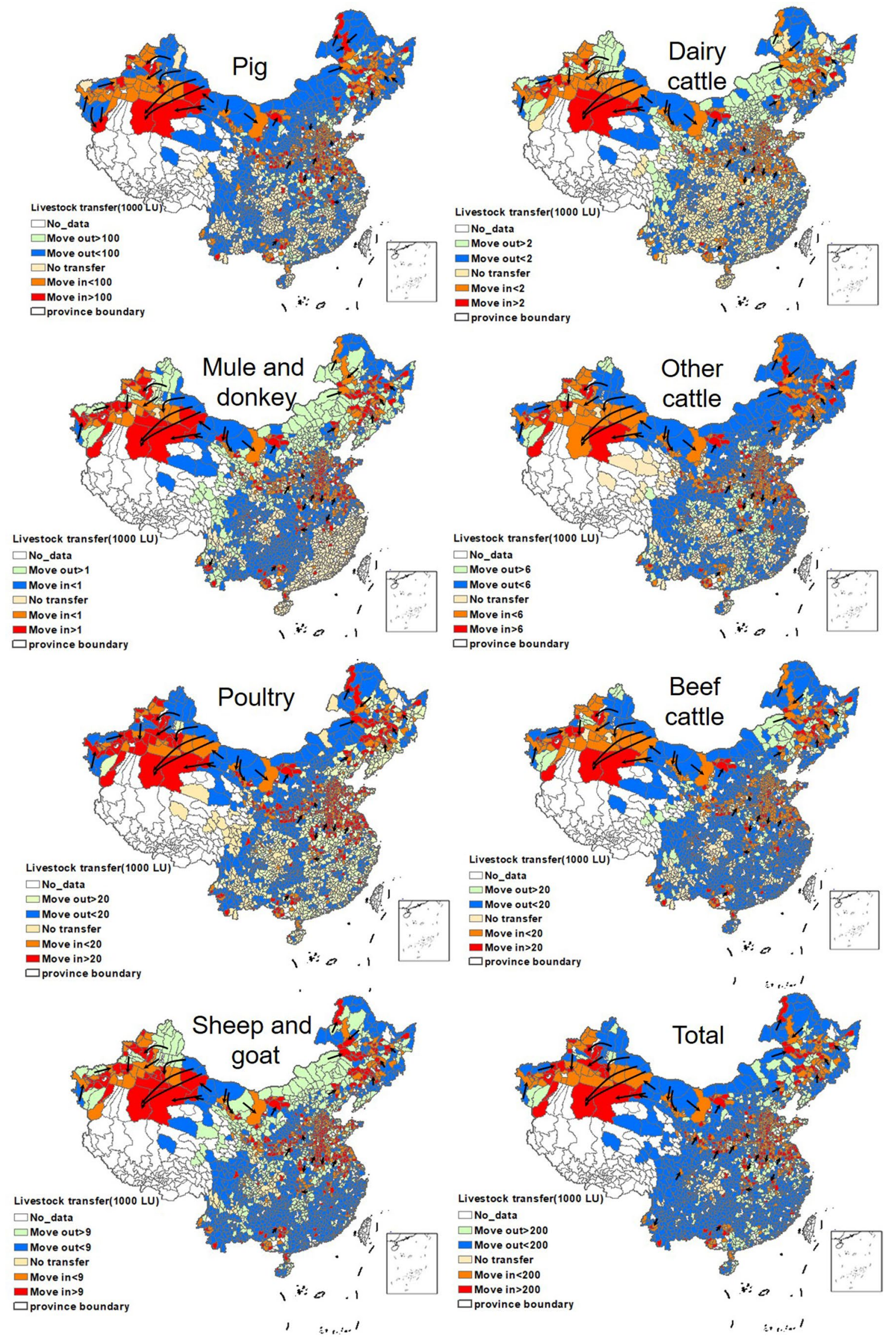

Extended Data Fig. 8 | See next page for caption. 
Extended Data Fig. 8 | Illustration of the relocation of livestock following the optimization of livestock spatial planning scenarios - SP-CLI in 2050.

Note: Arrows indicate the likely movement of animals from southeast to west and northwest, mainly via shutdown farms in the move out regions and build new farms in the move in regions. 

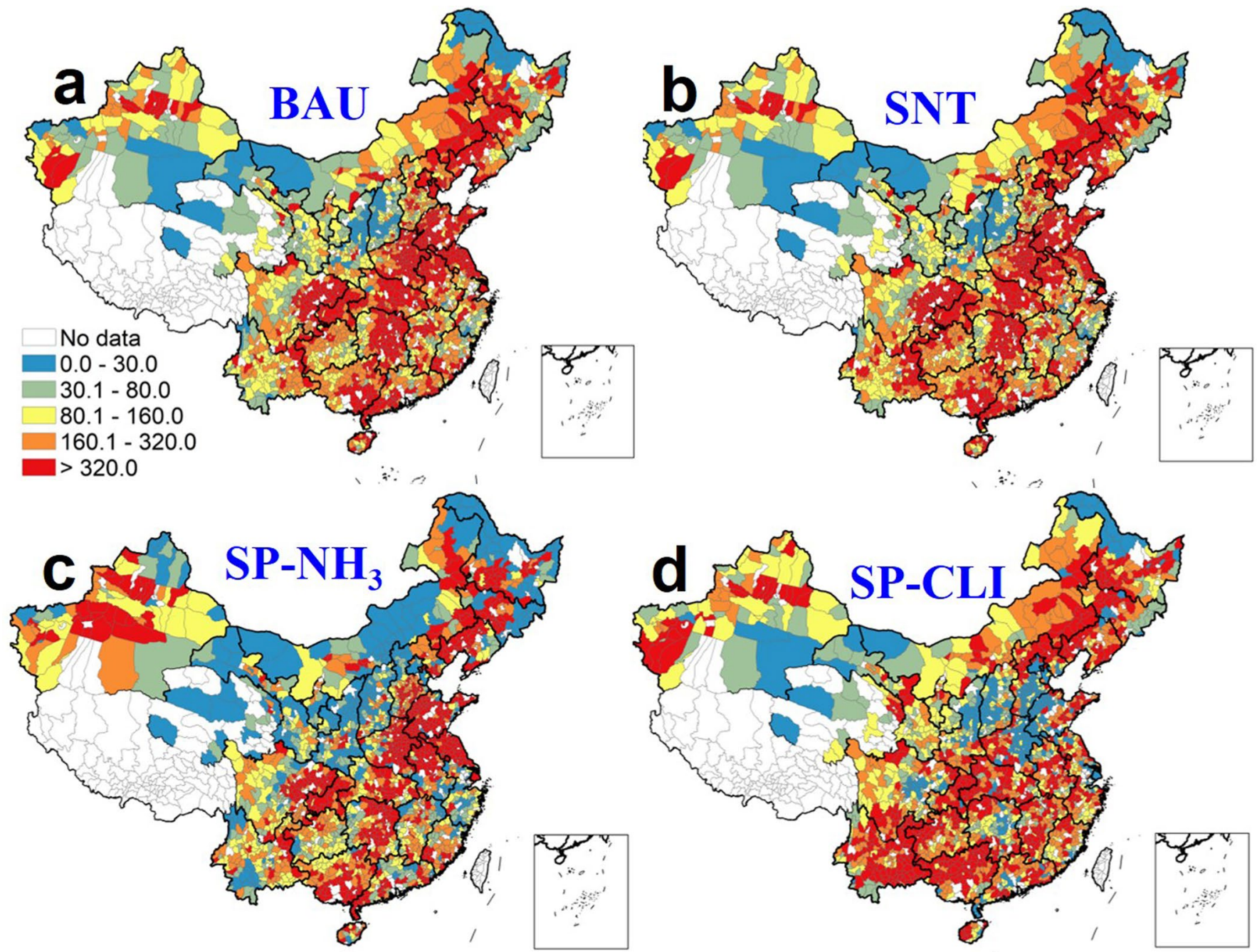

$\because \therefore$

Extended Data Fig. 9 | County level information about total livestock unit in the business as usual (BAU) scenario (a), south-north transfer of pig production (SNT) scenario (b) and spatial planning under the $\mathrm{NH}_{3}$ emission criteria (SP-NH$)$ scenario (c), and spatial planning under the crop-livestock integration scenario (SP-CLI) in 2050. Note: Definition of scenarios see Extended Data Fig. 1. 

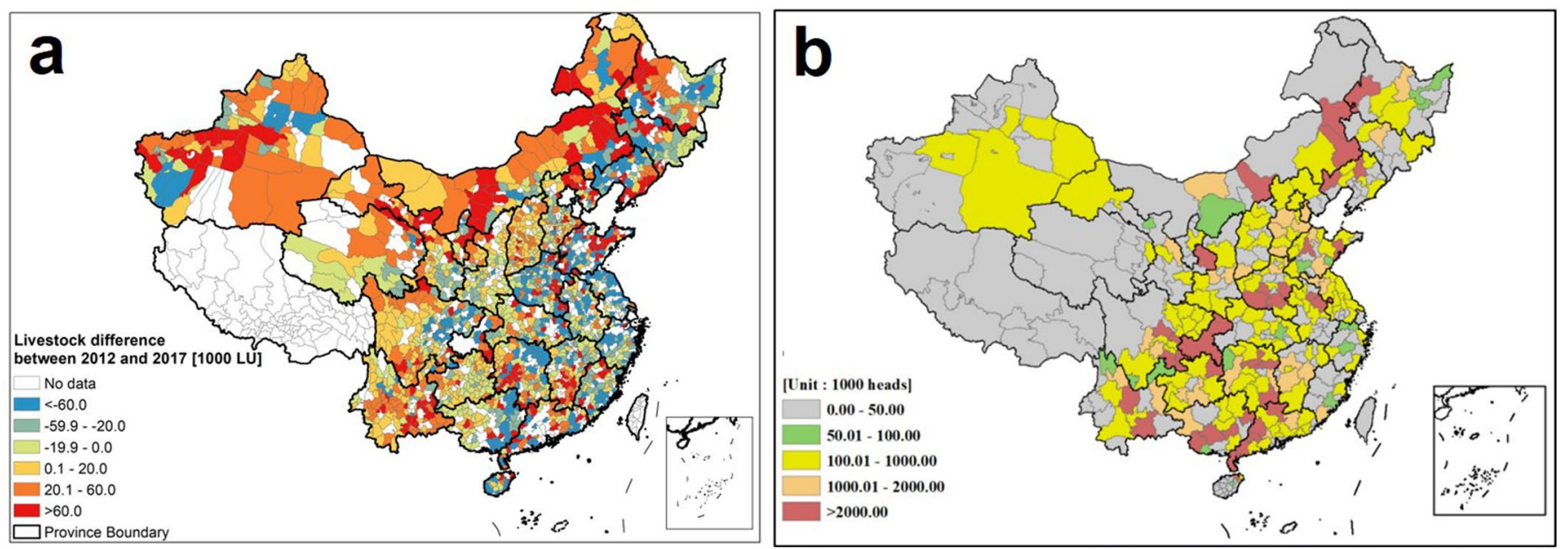

Extended Data Fig. 10 | Short-term changes of livestock production distribution between 2012 and 2017, and expansion plan of top pig production companies in 2020 . 


\section{Reporting Summary}

Nature Research wishes to improve the reproducibility of the work that we publish. This form provides structure for consistency and transparency in reporting. For further information on Nature Research policies, see our Editorial Policies and the Editorial Policy Checklist.

\section{Statistics}

For all statistical analyses, confirm that the following items are present in the figure legend, table legend, main text, or Methods section.

n/a Confirmed

Х $\square$ The exact sample size $(n)$ for each experimental group/condition, given as a discrete number and unit of measurement

Х $\square$ A statement on whether measurements were taken from distinct samples or whether the same sample was measured repeatedly

$\triangle \square$ The statistical test(s) used AND whether they are one- or two-sided

X Only common tests should be described solely by name; describe more complex techniques in the Methods section.

Х $\square$ A description of all covariates tested

Х $\square$ A description of any assumptions or corrections, such as tests of normality and adjustment for multiple comparisons

$\square$ A full description of the statistical parameters including central tendency (e.g. means) or other basic estimates (e.g. regression coefficient)

$\triangle$ AND variation (e.g. standard deviation) or associated estimates of uncertainty (e.g. confidence intervals)

$\triangle$ For null hypothesis testing, the test statistic (e.g. $F, t, r$ ) with confidence intervals, effect sizes, degrees of freedom and $P$ value noted

Х Give P values as exact values whenever suitable.

\ $\square$ For Bayesian analysis, information on the choice of priors and Markov chain Monte Carlo settings

Х $\square$ For hierarchical and complex designs, identification of the appropriate level for tests and full reporting of outcomes

Х $\square$ Estimates of effect sizes (e.g. Cohen's $d$, Pearson's $r$ ), indicating how they were calculated

Our web collection on statistics for biologists contains articles on many of the points above.

\section{Software and code}

Policy information about availability of computer code

Data collection County level data was collected from various type of statistic yearbook. Human population per county (https://data.cnki.net/Yearbook/Navi? type=type\&code=A) was derived from Statistics China; GDP per county (https://data.cnki.net/Yearbook/Navi?type=type\&code=A) was derived also from Statistics China; Availability of feed refers to total maize and soybean production per county and calculated by NUFER; Accessibility to feed refers to the road length per county and was derived from the website https://www.webmap.cn/commres.do?method=result100W; Water pollution sensitivity reflects the total length of surface rivers per county, and was derived from the website https://www.resdc.cn/ data.aspx?DATAID=226.

Data analysis Not applied.

For manuscripts utilizing custom algorithms or software that are central to the research but not yet described in published literature, software must be made available to editors and reviewers. We strongly encourage code deposition in a community repository (e.g. GitHub). See the Nature Research guidelines for submitting code \& software for further information.

\section{Data}

Policy information about availability of data

All manuscripts must include a data availability statement. This statement should provide the following information, where applicable:

- Accession codes, unique identifiers, or web links for publicly available datasets

- A list of figures that have associated raw data

- A description of any restrictions on data availability

All data needed to evaluate the conclusions in the paper are present in the paper and/or the Supplementary Materials. 


\section{Field-specific reporting}

Please select the one below that is the best fit for your research. If you are not sure, read the appropriate sections before making your selection.

Life sciences

Behavioural \& social sciences

Ecological, evolutionary \& environmental sciences

For a reference copy of the document with all sections, see nature.com/documents/nr-reporting-summary-flat.pdf

\section{Ecological, evolutionary \& environmental sciences study design}

All studies must disclose on these points even when the disclosure is negative.

Study description

The geographic segregation of crop and livestock production in China has been neglected in efforts to tackle nitrogen pollution of air and water. Here, we analyzed detailed statistical data available from 2300 counties for 1990 and 2012, and evaluated changes in nitrogen losses in response to changes in spatial distributions of livestock, using scenario analyses. Over $45 \%$ of livestock production was in counties with a livestock density $\geq 4.0$ livestock units ha- 1 , and $>60 \%$ of people were exposed to excessive ammonia emissions in 2012. Reallocation of livestock to reduce the exposure of people to ammonia led to increased nitrogen losses, because of less favorable production conditions in other counties. Reallocation of livestock according to crop-livestock integration criteria reduced nitrogen losses, but increased the exposure of people to ammonia. Spatial planning is a powerful policy instrument to tackle nitrogen pollution and exposure of humans to ammonia, but requires clear criteria agreed by stakeholders.

Research sample Data was collected from around 2300 counties in 1990 and 2012 by the authors, which also provided in Wang et al (2018). Hotspots for nitrogen and phosphorus losses from food production in China: a county-scale analysis. Environmental Science \& Technology, 52(10), 5782-5791.

Sampling strategy

Data from all counties have been used, to evaluate the uneven distribution of livestock production, and its impacts on regional $\mathrm{N}$ pollutions.

Data collection

Data was collected from around 2300 counties in 1990 and 2012 by the authors, which include information about the human population, crop production and livestock production.

Timing and spatial scale Data was collected from around 2300 counties in 1990 and 2012.

Data exclusions

No data was excluded.

Reproducibility

Not applicable.

Randomization

Not applicable.

Blinding

Not applicable.

Did the study involve field work? $\square$ Yes $\quad$ No

\section{Reporting for specific materials, systems and methods}

We require information from authors about some types of materials, experimental systems and methods used in many studies. Here, indicate whether each material, system or method listed is relevant to your study. If you are not sure if a list item applies to your research, read the appropriate section before selecting a response.

\begin{tabular}{|c|c|}
\hline$n / a$ & Involved in the study \\
\hline$\bigotimes$ & $\square$ Antibodies \\
\hline$\bigotimes$ & Eukaryotic cell lines \\
\hline Х & Palaeontology and archaeology \\
\hline$\bigotimes$ & Animals and other organisms \\
\hline$\bigotimes$ & Human research participants \\
\hline$\bigotimes$ & $\square$ Clinical data \\
\hline$\bigotimes$ & $\square$ Dual use research of concern \\
\hline
\end{tabular}

\begin{tabular}{l|l}
\multicolumn{2}{l}{ Methods } \\
\hline $\mathrm{n} / \mathrm{a}$ & Involved in the study \\
$\square$ & $\square$ ChIP-seq \\
$\square$ & $\square$ Flow cytometry \\
$\square$ & $\square$ MRI-based neuroimaging
\end{tabular} 